\title{
MODELO DE REFERÊNCIA PARA A GESTÃo ESTRATÉGICA DO DESEMPENHO DE PARQUES TECNOLÓGICOS ${ }^{1}$
}

\author{
Juliane de Almeida Ribeiro ${ }^{2}$ \\ Marcelo Bronzo Ladeira ${ }^{3}$ \\ Adriana Ferreira de Faria ${ }^{4}$
}

http://dx.doi.org/10.1590/1413-2311.232.84262

\section{RESUMO}

Parques tecnológicos são empreendimentos mundialmente reconhecidos como catalisadores do desenvolvimento econômico e social, por meio da promoção à inovação de base tecnológica, alcançada pela interação estratégica entre universidades, empresas e governos. Embora propostas tenham surgido nos últimos anos, não há concordância sobre um modelo sistemático para entender os parques tecnológicos e identificar a natureza de seu desempenho e sucesso. Assim, apesar do significativo número de parques tecnológicos, gestores e stakeholders desses empreendimentos ainda demandam o desenvolvimento e a utilização de sistemas de gestão e avaliação de desempenho mais robustos e eficazes. Este artigo apresenta o desenvolvimento de um modelo de referência para a gestão estratégica do desempenho de parques tecnológicos, baseado no Balanced Scorecard. No desenvolvimento do modelo, a abordagem teórica foi complementada com um estudo multi-casos exploratório e qualitativo com três parques tecnológicos brasileiros em operação. Para o aperfeiçoamento do modelo conceitual de referência, foi conduzido um levantamento com empresas residentes em

\footnotetext{
${ }^{1}$ Recebido em 26/06/2018, aprovado em 08/10/2018.

${ }^{2}$ Instituto Federal de Educação, Ciência e Tecnologia de Minas Gerais - Departamento de Administração; Ouro Branco - MG (Brasil) - juliane.ribeiro@ifmg.edu.br

${ }^{3}$ Universidade Federal de Minas Gerais - Faculdade de Ciências Econômicas e Centro de Pós-Graduação e Pesquisas em Administração; Belo Horizonte - MG (Brasil) - marcelobronzo@face.ufmg.br

${ }^{4}$ Universidade Federal de Viçosa - Departamento de Engenharia de Produção e Mecânica; Viçosa - MG (Brasil)

- adrianaf@ufv.br
} 
parques tecnológicos do País e, posteriormente, realizada a análise estatística dos dados. $\mathrm{O}$ modelo de referência resultante permite o estabelecimento de um referencial organizacional do sistema gerencial estratégico de um parque tecnológico.

Palavras-chave: Parques tecnológicos. Gestão estratégica de desempenho. Balanced scorecard. Análise fatorial exploratória.

\title{
REFERENCE MODEL FOR THE STRATEGIC PERFORMANCE MANAGEMENT OF TECHNOLOGY PARKS
}

\begin{abstract}
Technology parks are ventures globally recognized as catalysts for social and economic development, through the promotion of technology based innovation, reached as a result of the strategic interaction between universities, companies and the government. Although proposals have emerged in the last years, there is no consensus on a systematic model to understand technology parks and identify the nature of their performance and success. Thereby, despite the significant number of technology parks, managers and stakeholders still require the development and application of more robust and effective management models and performance assessment systems. This paper presents the development of a reference model for the strategic performance management of technology parks, based on the balanced scorecard. To develop this model, the theoretical approach was complemented by an exploratory and qualitative multicase study with three Brazilian technology parks in operation. To accomplish the improvement of the conceptual reference model, a survey with tenant companies of national technology parks was conducted and then a statistic data analysis took place. The reference model that has resulted allows the establishment of an organizational framework of the strategic management system of a technology park.
\end{abstract}

Keywords: Technology parks. Strategic performance management. Balanced scorecard. Exploratory factor analysis.

REAd | Porto Alegre - Vol. 24 - No 3 - Setembro / Dezembro 2018 - p. 183-216 


\title{
MODELO DE REFERENCIA PARA LA GESTIÓN ESTRATÉGICA DEL DESEMPEÑO DE PARQUES TECNOLÓGICOS
}

\begin{abstract}
RESUMEN
Los parques tecnológicos son emprendimientos mundialmente reconocidos como catalizadores del desarrollo económico y social, a través de la promoción a la innovación de base tecnológica, alcanzada por la interacción estratégica entre universidades, empresas y gobiernos. Aunque propuestas hayan surgido en los últimos años, no existe concordancia sobre un modelo sistemático para entender los parques tecnológicos e identificar la naturaleza de su desempeño y éxito. Así, a pesar del significativo número de parques tecnológicos, gestores y stakeholders de esos emprendimientos todavía demandan el desarrollo y la utilización de sistemas de gestión y evaluación de desempeño que sean más robustos y eficaces. Este artículo presenta el desarrollo de un modelo de referencia para la gestión estratégica del desempeño de parques tecnológicos, basado en el Balanced Scorecard. Para el desarollo del modelo, el abordaje teórico fue complementado con un estudio multicasos exploratorio y cualitativo con tres parques tecnológicos brasileños en operación. Para el delineamiento del modelo conceptual de referencia, fue conducida una encuesta con empresas residentes en parques tecnológicos del país y posteriormente se realizó el análisis estadístico de los datos. El modelo de referencia resultante permite el estabelecimiento de un framework del sistema gerencial estratégico de un parque tecnológico.
\end{abstract}

Palabras-clave: Parques tecnológicos. Gestión estratégica del desempeño. Balanced Scorecard. Análisis factorial exploratório.

\section{INTRODUÇÃO}

Em uma economia baseada no conhecimento, os parques tecnológicos têm se destacado como mecanismos para impulsionar o desenvolvimento sustentável, por meio da inovação. Quando baseados no modelo da Hélice Tríplice de interação universidadeindústria-governo (ETZKOWITZ, 2003; ETZKOWITZ; LEYDESDORFF, 1999), esses empreendimentos atuam como catalisadores do desenvolvimento econômico, facilitando a criação e o desenvolvimento de empresas de base tecnológica e a transferência de conhecimento entre universidades e empresas (VILÀ; PAGÈS, 2008).

REAd | Porto Alegre - Vol. 24 - No 3 - Setembro / Dezembro 2018 - p. 183-216 
Há uma agenda para avaliação da efetividade dos parques tecnológicos (FERNANDES, 2014), envolvendo questões como alinhamento e integração de atores e organizações, avaliação de desempenho, transparência para a sociedade em relação aos recursos públicos investidos e identificação de oportunidades de melhoria nos processos de gestão e de inovação (BIGLIARDI et al., 2006; DABROWSKA, 2011; FERRARA; LAMPERTI; MAVILIA, 2016; MONCK; PETERS, 2009). Uma melhor e mais efetiva gestão dos parques tecnológicos requer o desenvolvimento de ferramentas e sistemas de avaliação que possam ser implantados com mais facilidade por parte dos gestores, e que sejam aceitos pelos stakeholders (BIGLIARDI et al., 2006; DABROWSKA, 2011; FERNANDES，2014; FERRARA; LAMPERTI; MAVILIA，2016; RODEIRO-PAZOS; CALVO-BABIO, 2012).

Em relação à avaliação de desempenho dos parques tecnológicos, o assunto tem sido investigado sob três enfoques principais (VEDOVELLO; JUDICE; MACULAN, 2006): (i) análise da interação universidade-empresa; (ii) localização das empresas e seu desempenho; e (iii) desenvolvimento de indicadores de desempenho e sistemas de avaliação. Em relação a este último, destacam-se os trabalhos de Bigliardi et al. (2006), Dabrowska (2011), Fernandes (2014) e Ferrara, Lamperti e Mavilia (2016), que propõem e validam indicadores de desempenho em determinadas áreas de resultados.

No caso desta pesquisa, buscou-se construir um sistema de avaliação baseado no Balanced Scorecard (BSC), adaptado ao ecossistema dos parques tecnológicos, considerando os recursos de seus principais stakeholders (universidades, governo, equipe de gestão e empresas residentes) como ponto de partida para a proposição dos indicadores. Inicialmente, a pesquisa envolveu a realização de um estudo multi-casos, com três parques tecnológicos no Brasil, em que foram identificadas as dimensões de análise e os indicadores relevantes para a construção do modelo conceitual de referência da pesquisa. Em seguida, com o propósito de aperfeiçoamento do modelo, foi realizado um survey com empresários e gestores das empresas residentes dos parques investigados e, posteriormente, foi realizada a análise estatística dos dados.

O modelo conceitual de referência para a gestão estratégica do desempenho de parques tecnológicos, após as devidas análises exploratórias e de confiabilidade, apresenta 22 indicadores que refletem os recursos mais importantes oferecidos pelos principais atores que compõem o ecossistema do parque tecnológico, bem como os indicadores de resultado mais relevantes para gestão estratégica do desempenho desses empreendimentos, de acordo com a visão das empresas residentes nos parques tecnológicos. $\mathrm{O}$ modelo proposto e aperfeiçoado 
empiricamente permite o estabelecimento de um referencial organizacional do sistema gerencial estratégico de um parque tecnológico.

Além dessa introdução, esse artigo está estruturado inicialmente por uma seção de marco teórico, em que é realizada a revisão de literatura sobre parques tecnológicos, Balanced Scorecard (BSC) e modelos de avaliação de desempenho para parques tecnológicos. Em seguida, na seção dois, estão descritos os aspectos metodológicos do trabalho e o modelo teórico-conceitual da pesquisa, explicitando a sua base lógica e a operacionalização dos construtos. A seção três apresenta a discussão dos principais resultados da pesquisa. Posteriormente, descrevem-se as considerações finais do estudo, incluindo a proposição de novas questões para trabalhos futuros.

\section{REFERENCIAL TEÓRICO \\ 1.1 PARQUES TECNOLÓGICOS}

Atribui-se a origem do conceito de parque tecnológico as notórias experiências espontâneas de aglomeração espacial e de sucesso tecnológico do Vale do Silício, na Califórnia, e da Rota 128, na região de Boston, Massachusetts, entre 1940 e 1960 (CASTELLS; HALL, 1994; SAXENIAN, 1985). O sucesso dessas primeiras experiências norte-americanas contribuiu decisivamente para a evolução e construção do conceito de parque tecnológico, bem como para o desenvolvimento de experiências de emulação na Europa, com destaque para a implantação dos parques pioneiros britânicos (Cambridge) e franceses (Sophia-Antipolis), no fim dos anos de 1960 e início dos de 1970 (CASTELLS; HALL, 1994).

No Brasil, esse movimento ganha impulso apenas a partir da década de 1990, e, portanto, é relativamente recente, se comparado com Estados Unidos e Europa. Segundo levantamento do Ministério de Ciência, Tecnologia, Inovações e Telecomunicações (MCTIC, 2013), o País conta com aproximadamente uma centena de iniciativas de parques tecnológicos, divididas nas fases de projeto, implantação e operação. Conforme o estudo foram identificados 28 empreendimentos em operação, 939 empresas em funcionamento e 32,2 mil empregos gerados em empresas e institutos de pesquisa residentes nos parques tecnológicos, bem como na equipe de gestão desses empreendimentos.

De acordo com a ANPROTEC (2018), parque tecnológico pode ser entendido como um espaço planejado e cooperativo, no qual ocorre a interação entre empresas de base tecnológica e outras empresas, instituições de ensino, pesquisa e desenvolvimento. Cabe ao 
parque oferecer serviços de alto valor agregado para promover a cultura da inovação, a competitividade e o aumento da capacitação empresarial, buscando fomentar a criação de riquezas na região. Os principais atores envolvidos com os parques tecnológicos, as suas contribuições e os resultados esperados podem ser visualizados no Quadro 1.

\section{Quadro 1 - Parques tecnológicos: stakeholders, contribuições e resultados esperados}

\begin{tabular}{|c|c|c|}
\hline Stakeholders & Principais contribuições & Resultados esperados \\
\hline $\begin{array}{l}\text { Universidades e } \\
\text { institutos de } \\
\text { pesquisa }\end{array}$ & $\begin{array}{l}\text { Base científica: capital humano, } \\
\text { infraestrutura tecnológica e capital } \\
\text { organizacional. } \\
\text { Capacidade de atrair empresas e } \\
\text { talentos. }\end{array}$ & $\begin{array}{l}\text { Comercializar resultados de pesquisa } \\
\text { acadêmica, ampliando as fontes de } \\
\text { recursos financeiros. } \\
\text { Ampliar a missão institucional. } \\
\text { Ampliar o mercado de trabalho para } \\
\text { pesquisadores e estudantes. }\end{array}$ \\
\hline $\begin{array}{l}\text { Empresários e } \\
\text { acadêmicos- } \\
\text { empresários }\end{array}$ & $\begin{array}{l}\text { Cultura empreendedora, conheci- } \\
\text { mento técnico e de mercado. }\end{array}$ & $\begin{array}{l}\text { Utilizar resultados das atividades } \\
\text { acadêmicas e de pesquisa de forma a } \\
\text { potencializar as próprias atividades de } \\
\text { P\&D empresarial. } \\
\text { Potencializar retornos financeiros. } \\
\text { Acessar recursos humanos } \\
\text { qualificados. }\end{array}$ \\
\hline $\begin{array}{l}\text { Equipe de gestão } \\
\text { do parque } \\
\text { tecnológico }\end{array}$ & $\begin{array}{l}\text { Parcerias, eventos, networking, } \\
\text { capacitação empresarial. }\end{array}$ & $\begin{array}{l}\text { Crescimento do faturamento das } \\
\text { empresas do parque tecnológico. } \\
\text { Melhoria na reputação do } \\
\text { empreendimento. } \\
\text { Atração de grandes empresas e de } \\
\text { novos investimentos públicos e } \\
\text { privados. }\end{array}$ \\
\hline $\begin{array}{l}\text { Agentes financeiros } \\
\text { e investidores de } \\
\text { oportunidade } \\
\text { (risco) }\end{array}$ & $\begin{array}{l}\text { Disponibilidade de financiamento } \\
\text { e apoio técnico e gerencial para } \\
\text { empresas. }\end{array}$ & $\begin{array}{l}\text { Investir em novas empresas de base } \\
\text { tecnológica com alto e rápido potencial } \\
\text { de crescimento econômico e retornos } \\
\text { financeiros. }\end{array}$ \\
\hline $\begin{array}{l}\text { Governo e agências } \\
\text { de desenvolvimento }\end{array}$ & $\begin{array}{l}\text { Suporte político, recursos públicos } \\
\text { para estruturação e operação dos } \\
\text { parques e financiamentos atrativos } \\
\text { para impulsionar as empresas. }\end{array}$ & $\begin{array}{l}\text { Apoiar atividades inovadoras nas } \\
\text { empresas. } \\
\text { Revitalizar regiões economicamente } \\
\text { deprimidas. } \\
\text { Gerar empregos. }\end{array}$ \\
\hline
\end{tabular}

Fonte: adaptado de Vedovello, Judice e Maculan (2006).

Em se tratando dos desafios para o desenvolvimento dos parques tecnológicos no Brasil, um estudo do MCTIC (2015) avalia que a melhoria das políticas de apoio a parques tecnológicos passa pela definição de critérios de enquadramento nas distintas fases de desenvolvimento (planejamento, instalação e operação) e indicadores de desempenho para investimento de recursos públicos, bem como pela elaboração de um sistema de avaliação de desempenho de parques tecnológicos. 
A proposição de um mecanismo de avaliação e gestão de desempenho desses ambientes de inovação é uma tarefa complexa, devido a variedade de stakeholders, propostas de valor e expectativas envolvidas. Assim, a utilização de um modelo multidimensional de gestão estratégica de desempenho, como o BSC, que concilie as contribuições e os resultados esperados de cada ator, pode ser um caminho válido para o entendimento da integração de recursos e da cocriação de valor no ecossistema de parques tecnológicos.

\subsection{BALANCED SCORECARD (BSC)}

Nos anos 1990, os métodos tradicionalmente utilizados para a mensuração do desempenho empresarial passaram a ser questionados em sua eficácia. Grande parte das críticas estava no fato de que esses métodos eram, quase sempre, constituídos por indicadores contábeis e financeiros das empresas, não havendo uma consideração mais ampla de potenciais áreas do desempenho. Tais limitações objetivas foram superadas com o desenvolvimento de uma nova ferramenta gerencial denominada Balanced Scorecard (BSC) (KAPLAN; NORTON, 1992). O nome Balanced Scorecard foi escolhido porque o modelo refletia o equilíbrio entre objetivos de curto e longo prazos, entre medidas financeiras e não financeiras, entre indicadores de tendências e resultados e entre as perspectivas interna e externa de desempenho. O BSC propôs a integração de objetivos, indicadores, metas e iniciativas em quatro categorias interligadas de desempenho: financeira, dos clientes, dos processos internos, e do aprendizado e crescimento (KAPLAN; NORTON, 1992).

A perspectiva financeira é a responsável por definir o desempenho financeiro esperado a partir da execução das estratégias do negócio, e por fornecer as principais metas para os objetivos e medidas de todas as outras perspectivas do scorecard. O desempenho financeiro reflete os resultados tangíveis da estratégia, indicando se a organização está caminhando para uma situação de sucesso. Diferentes temas podem orientar essa perspectiva: crescimento e mix de receita, redução de custos/melhoria de produtividade e aumento da utilização dos ativos (KAPLAN; NORTON, 1997).

A melhoria do desempenho financeiro está fortemente relacionada ao êxito no atendimento das demandas e necessidades dos clientes da organização. A perspectiva do cliente estabelece a proposição de valor da organização, que define o contexto para que os ativos intangíveis e processos internos criem valor (KAPLAN; NORTON, 2004). O bom desempenho dessa perspectiva pode ser mensurado por indicadores, como índices de satisfação e retenção de clientes, ou crescimento do market share, por exemplo. 
Enquanto a perspectiva financeira e a do cliente descrevem os resultados que se esperam da execução da estratégia (constituem faces externas do desempenho), a dimensão de processos internos identifica os poucos processos críticos que devem exercer o maior impacto sobre a estratégia (KAPLAN; NORTON, 2004). São esses processos que vão criar e cumprir a proposição de valor para os clientes e indicar tendências de melhorias, que terão impacto junto ao público-alvo e nos resultados financeiros.

$\mathrm{Na}$ base do BSC, a perspectiva de aprendizado e crescimento define os ativos intangíveis mais importantes para a execução das estratégias do negócio. Os objetivos nessa perspectiva identificam que cargos (o capital humano), que sistemas (o capital da informação) e que tipo de clima (o capital organizacional) são necessários para sustentar os processos internos de criação de valor. Esses ativos devem ser conectados coerentemente uns com os outros, e então alinhados aos processos internos críticos (KAPLAN; NORTON, 2004).

As quatro perspectivas citadas podem ser complementadas por outras, desde que estas sejam consideradas estratégicas no contexto da organização (KAPLAN; NORTON, 1997). Instituições do setor público e entidades sem fins lucrativos também fazem uso do BSC. A diferença é que, nesse caso, o critério definitivo de sucesso não é o desempenho financeiro, ou a criação de valor sustentável para os acionistas, mas o desempenho no cumprimento da missão, obtido por meio da criação de valor sustentável para dois grupos de interesse: contribuintes e beneficiários (KAPLAN; NORTON, 2004).

\subsection{AVALIAÇÃO DE DESEMPENHO DE PARQUES TECNOLÓGICOS}

Ainda que os parques tecnológicos sejam reconhecidos como elementos-chave da política de desenvolvimento regional baseada na pesquisa e inovação (SAUBLENS et al., 2007), avaliar seu desempenho é uma tarefa complexa (FERRARA; LAMPERTI; MAVILIA, 2016), caracterizada pela proposição de abordagens que não podem ser generalizadas (BIGLIARDI et al., 2006; DABROWSKA, 2011; PHAN; SIEGEL; WRIGHT, 2005; VEDOVELLO; JUDICE; MACULAN, 2006). Embora histórias de sucesso possam ser destacadas, não há consenso sobre uma abordagem sistemática para avaliar os parques tecnológicos e identificar a natureza de seu desempenho (DABROWSKA, 2011; PHAN; SIEGEL; WRIGHT, 2005; RATINHO; HENRIQUES, 2010).

$\mathrm{Na}$ literatura sobre o tema, três enfoques principais de pesquisa podem ser citados (VEDOVELLO; JUDICE; MACULAN, 2006), conforme o Quadro 2.

REAd | Porto Alegre - Vol. 24 - No 3 - Setembro / Dezembro 2018 - p. 183-216 
Quadro 2 - Enfoque dos estudos de avaliação sobre parques tecnológicos

\begin{tabular}{|c|l|}
\hline Enfoque & \multicolumn{1}{|c|}{ Forma de avaliação } \\
\hline $\begin{array}{c}\text { Interação universidade- } \\
\text { empresa }\end{array}$ & $\begin{array}{l}\text { Avaliação da natureza e frequência das interações entre empresas } \\
\text { residentes no parque tecnológico e a universidade âncora e seus } \\
\text { pesquisadores. Avaliação dos resultados das interações entre os atores. }\end{array}$ \\
\hline $\begin{array}{c}\text { Localização de } \\
\text { empresas e seu } \\
\text { desempenho }\end{array}$ & $\begin{array}{l}\text { Comparação entre o desempenho de empresas residentes em parques } \\
\text { tecnológicos e empresas de base tecnológica similares, mas localizadas } \\
\text { fora dos parques tecnológicos. Geralmente comparam-se os indicadores: } \\
\text { número de empregos criados, vendas, lucratividade, resultados de P\&D, } \\
\text { novos produtos e serviços e taxa de sobrevivência das empresas. }\end{array}$ \\
\hline $\begin{array}{c}\text { Avaliação de } \\
\text { desempenho de parques }\end{array}$ & $\begin{array}{l}\text { Quase sempre se propõem modelos de avaliação genéricos, orientados } \\
\text { para considerar o ambiente difuso que permeia a implementação, o } \\
\text { desenvolvimento e a operacionalização dos parques tecnológicos. }\end{array}$ \\
\hline
\end{tabular}

Fonte: adaptado de Vedovello, Judice e Maculan (2006).

Em se tratando do terceiro tipo, as propostas de avaliação de desempenho podem adotar um enfoque mais amplo e complexo, ressaltando os impactos dos parques tecnológicos sobre a microeconomia da região (BIGLIARDI et al., 2006; MONCK; PETERS, 2009), ou um enfoque mais específico e pragmático, voltado principalmente para a gestão de desempenho do parque tecnológico (DABROWSKA, 2011; RODEIRO-PAZOS; CALVOBABIO, 2012). Alguns estudos buscam identificar dimensões e indicadores de desempenho a partir da revisão da literatura (BIGLIARDI et al., 2006; FERRARA; LAMPERTI; MAVILIA, 2016) e outros a partir de adaptações de metodologias como o BSC e os mapas estratégicos (DABROWSKA, 2011; RODEIRO-PAZOS; CALVO-BABIO, 2012).

A importância das empresas residentes é destacada em vários trabalhos, indicando a centralidade desse ator no ecossistema dos parques tecnológicos. A literatura também identifica modelos de avaliação e indicadores de desempenho a partir de fatores críticos de sucesso para esses empreendimentos, tais como: infraestrutura de qualidade; nível e quantidade de serviços à disposição dos empreendedores; gestão da imagem e marca do parque; alianças com atores estratégicos, entre outros (DABROWSKA, 2011; FERNANDES, 2014; RODEIRO-PAZOS; CALVO-BABIO, 2012). Todos esses elementos dão suporte ao modelo proposto nesse trabalho, apresentado na próxima seção. 


\section{MÉTOdo DE PESQUISA, MODELO CONCEITUAL DE REFERÊNCIA E INDICADORES PROPOSTOS}

O método de pesquisa adotado para o desenvolvimento do modelo conceitual de referência está representado na Figura 1. Essa pesquisa foi realizada em duas etapas, uma de natureza exploratória e qualitativa, e a outra de natureza quantitativa e descritiva.

\section{Figura 1 - Método de pesquisa para o desenvolvimento do modelo conceitual de referência}

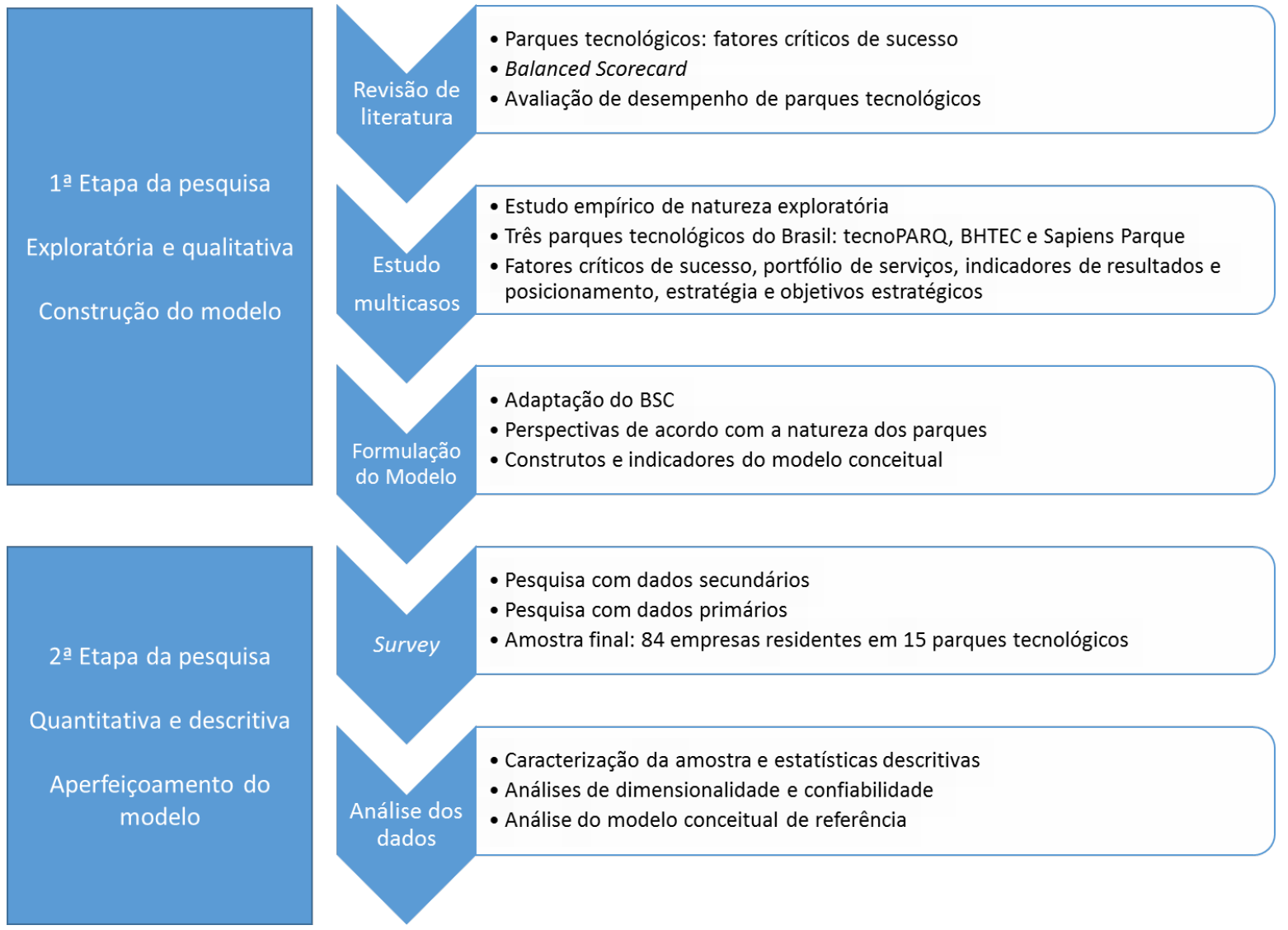

Fonte: elaborado pelos autores.

Inicialmente, realizou-se um estudo multi-casos, visando ao entendimento do contexto no qual os parques tecnológicos se desenvolvem e à identificação das variáveis causais que mais contribuem para explicar o seu desempenho. Nesse estudo, adotou-se uma amostragem por conveniência, na qual foram pesquisados os seguintes parques tecnológicos: tecnoPARQ (Viçosa - MG), BH-TEC (Belo Horizonte - MG) e Sapiens Parque (Florianópolis - SC).

Como principal instrumento de coleta de dados para o estudo multi-casos, elaborou-se um roteiro semiestruturado de perguntas, a partir da revisão de literatura (esse Roteiro se 
encontra disponível como Apêndice ao final do artigo). Foram realizadas sete entrevistas nos três parques tecnológicos, com gestores de nível tático e estratégico dos empreendimentos. Para tal, foram realizados alguns contatos prévios, nos quais foram apresentados o escopo do estudo, os seus objetivos e o roteiro de entrevistas. Informações detalhadas sobre o perfil dos entrevistados são apresentadas no Quadro 3.

\section{Quadro 3 - Informações sobre os entrevistados}

\begin{tabular}{|c|c|c|c|}
\hline Entrevistado(a) & Cargo & Escolaridade & $\begin{array}{c}\text { Tempo no } \\
\text { parque }\end{array}$ \\
\hline $\mathrm{E} 1^{1}$ & $\begin{array}{l}\text { Coordenador } \\
\text { TecnoPARQ }\end{array}$ & $\begin{array}{l}\text { Pós-graduação em } \\
\text { Engenharia de Segurança do } \\
\text { Trabalho (UFV) }\end{array}$ & Desde 2013 \\
\hline $\mathrm{E} 2^{1}$ & Gerente de novos negócios & $\begin{array}{l}\text { Mestrado em Fisiologia } \\
\text { Vegetal (UFV) }\end{array}$ & De 2011 à 2015 \\
\hline $\mathrm{E} 3^{1}$ & $\begin{array}{l}\text { Gerente } \\
\text { acompanhamento } \\
\text { empresarial }\end{array}$ & $\begin{array}{l}\text { Graduação em Ciências } \\
\text { Econômicas (UFV) }\end{array}$ & Desde 2012 \\
\hline $\mathrm{E} 4^{1}$ & $\begin{array}{l}\text { Gerente de relações } \\
\text { internacionais }\end{array}$ & $\begin{array}{l}\text { Pós-graduação em Gestão } \\
\text { Estratégica (USP) }\end{array}$ & Desde 2014 \\
\hline $\mathrm{E} 5^{2}$ & Gestora executiva & $\begin{array}{l}\text { Mestrado em Engenharia de } \\
\text { Produção (UFMG) }\end{array}$ & Desde 2003 \\
\hline $\mathrm{E} 6^{2}$ & Diretor presidente & $\begin{array}{l}\text { PhD em Engenharia Elétrica } \\
\text { (Texas University) }\end{array}$ & $\begin{array}{l}\text { De } 2010 \\
03 / 2018\end{array}$ \\
\hline$E 7^{3}$ & Gestora executiva & $\begin{array}{l}\text { Pós-Graduação em Gestão de } \\
\text { Negócios (FGV) }\end{array}$ & Desde 2009 \\
\hline
\end{tabular}

Fonte: elaborado pelos autores.

Nota: ${ }^{1}$ TecnoPARQ, ${ }^{2}$ BH-TEC, ${ }^{3}$ Sapiens Parque.

Para a análise dos dados obtidos nas entrevistas, utilizou-se a técnica de análise de conteúdo - mais especificamente, a análise temática. De acordo com Bardin (2000, p. 106), "as respostas a questões abertas [...] podem ser, e são frequentemente, analisadas tendo o tema por base". Dessa forma, informações afins das entrevistas foram agrupadas em quatro categorias temáticas: (i) fatores críticos de sucesso; (ii) portfólio de serviços; (iii) indicadores de resultados; e (iv) posicionamento, estratégia e objetivos estratégicos dos parques.

Com base nesses resultados, desenvolveu-se o modelo conceitual da pesquisa, estruturado com os cinco construtos propostos e seus respectivos indicadores. O modelo conceitual de referência foi proposto a partir de uma adaptação do BSC para o contexto da gestão estratégica de parques tecnológicos. Nesse caso, as perspectivas foram definidas considerando a natureza dos parques tecnológicos e de seus principais stakeholders: equipe 
de gestão do parque, governo, empresas residentes e universidades, conforme representado na Figura 2. As perspectivas definidas podem ser entendidas como dimensões latentes ou construtos que resumem ou explicam um conjunto original de variáveis propostas (indicadores). Formulou-se, assim, o modelo conceitual de referência que foi, então, testado por meio de um survey, numa segunda fase da pesquisa.

Figura 2 - Representação do modelo conceitual de referência da pesquisa

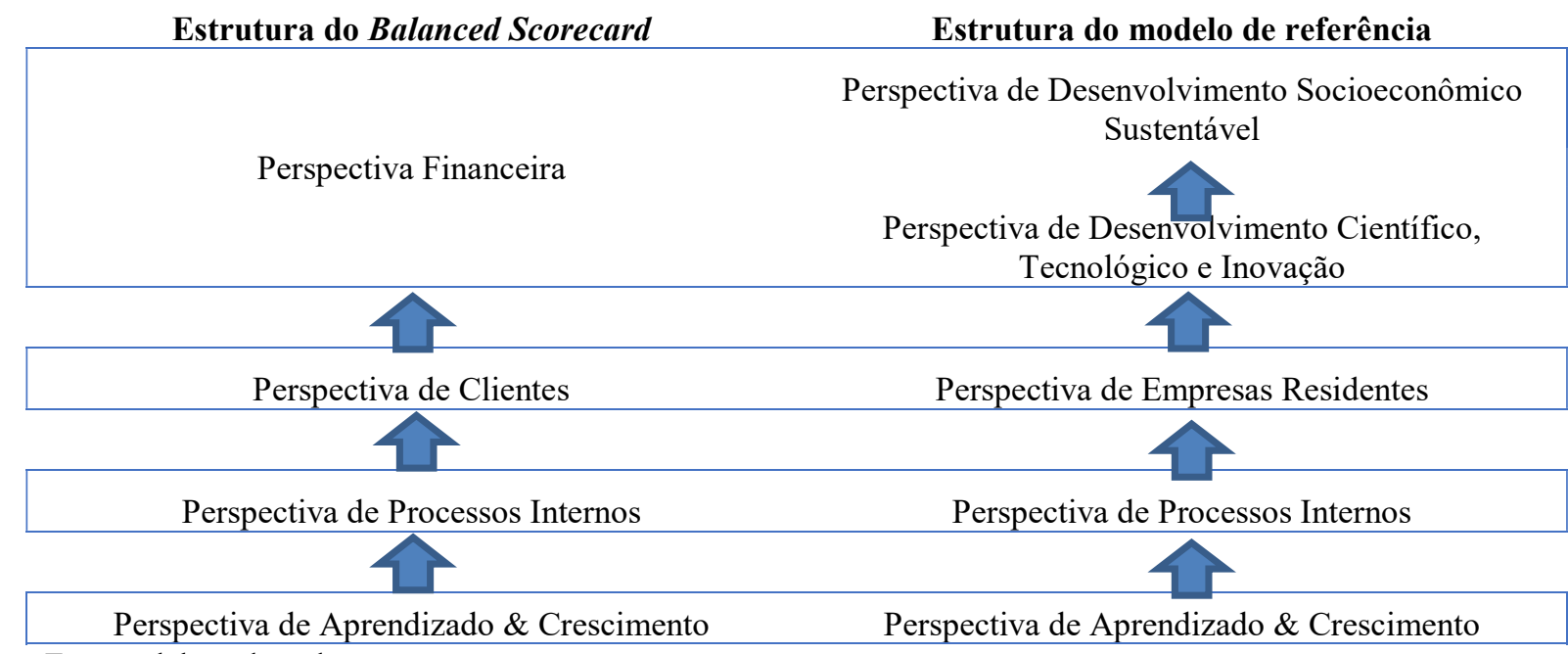
Fonte: elaborado pelos autores.

O desempenho da equipe de gestão e do governo, no que se refere à provisão das bases de suporte para o desempenho das empresas, é diretamente vinculado às perspectivas de "aprendizado e crescimento" e de "processos internos". A proposição de valor cocriada por esses stakeholders é mensurada na perspectiva das "empresas residentes", definidas como atores focais do modelo. A perspectiva financeira do BSC, por sua vez, está desdobrada em duas: "desenvolvimento científico, tecnológico e inovação", que mede a intensidade e os resultados da relação universidade-empresa, e "desenvolvimento socioeconômico sustentável", que mensura os benefícios mais holísticos do parque para a região em que ele se insere. Os construtos desenvolvidos, e seus respectivos conceitos, estão apresentados no Quadro 4. 


\section{Quadro 4 - Construtos do modelo}

\begin{tabular}{|c|c|c|}
\hline Construto/Perspectiva & Pergunta-chave & Conceito \\
\hline $\begin{array}{l}\text { Aprendizado e } \\
\text { crescimento }\end{array}$ & $\begin{array}{l}\text { Quais são as condições que } \\
\text { podem influenciar a estruturação } \\
\text { e o desempenho de um parque } \\
\text { tecnológico? }\end{array}$ & $\begin{array}{l}\text { Refere-se aos fatores críticos de } \\
\text { sucesso ou aos ativos, tangíveis e } \\
\text { intangíveis, requeridos para que o } \\
\text { empreendimento seja bem-sucedido. }\end{array}$ \\
\hline Processos internos & $\begin{array}{l}\text { Quais são os processos de } \\
\text { serviços e as ações que o parque } \\
\text { pode estabelecer e executar para } \\
\text { promover o desempenho das } \\
\text { empresas? }\end{array}$ & $\begin{array}{l}\text { Refere-se às atividades relacionadas à } \\
\text { organização, à coordenação e aos } \\
\text { serviços de valor agregado mais } \\
\text { relevantes oferecidos pelo parque, } \\
\text { tendo em vista o crescimento das } \\
\text { empresas e do empreendimento. }\end{array}$ \\
\hline Empresas residentes & $\begin{array}{l}\text { Quais são os aspectos da proposta } \\
\text { de valor oferecida pelo parque } \\
\text { que podem impactar o } \\
\text { desempenho das empresas e, } \\
\text { portanto, o sucesso do parque? }\end{array}$ & $\begin{array}{l}\text { Refere-se à proposta de valor do } \\
\text { parque para as empresas residentes. } \\
\text { Consiste em uma avaliação do } \\
\text { desempenho do parque como um } \\
\text { facilitador da inovação tecnológica e } \\
\text { do desenvolvimento de negócios, } \\
\text { assim como em sua efetividade na } \\
\text { provisão de soluções de valor para as } \\
\text { empresas. }\end{array}$ \\
\hline $\begin{array}{l}\text { Desenvolvimento } \\
\text { científico, tecnológico e } \\
\text { inovação }\end{array}$ & $\begin{array}{l}\text { Quais são as ações que o parque } \\
\text { pode realizar para contribuir com } \\
\text { a construção de universidades } \\
\text { empreendedoras e com o } \\
\text { desenvolvimento científico e } \\
\text { tecnológico do país? }\end{array}$ & $\begin{array}{l}\text { Refere-se ao trabalho do parque } \\
\text { como um incentivador da relação } \\
\text { universidade-empresa, na busca de } \\
\text { desenvolvimento } \\
\text { tecnológico e inovações }\end{array}$ \\
\hline $\begin{array}{l}\text { Desenvolvimento } \\
\text { socioeconômico } \\
\text { sustentável }\end{array}$ & $\begin{array}{l}\text { Quais são as diretrizes do parque, } \\
\text { que desdobradas em objetivos, } \\
\text { podem contribuir com o } \\
\text { desenvolvimento sustentável da } \\
\text { região? }\end{array}$ & $\begin{array}{l}\text { Refere-se aos resultados mais } \\
\text { holísticos do empreendimento na } \\
\text { região em que está inserido, } \\
\text { contemplando benefícios de natureza } \\
\text { socioeconômica e ambiental }\end{array}$ \\
\hline
\end{tabular}

Fonte: adaptado de Ribeiro et al. (2016).

Em relação à operacionalização dos construtos, houve a preocupação de que os indicadores demonstrassem consistência com o BSC e com o contexto de parques tecnológicos. O Quadro 5 apresenta os indicadores propostos para o modelo conceitual de referência desta pesquisa. 


\section{Quadro 5 - Modelo conceitual de referência: construtos e indicadores propostos}

\begin{tabular}{|c|c|c|}
\hline Construtos & $\begin{aligned} & \text { Indicadores propostos } \\
&\end{aligned}$ & Referências \\
\hline $\begin{array}{l}\text { Aprendizado e } \\
\text { crescimento }\end{array}$ & $\begin{array}{l}\text { 1.1 } \text { Forte base científica e tecnológica. } \\
\text { 1.2 Cultura empreendedora da região. } \\
\text { 1.3 Cultura inovadora da região. } \\
\text { 1.4 Economia regional forte. } \\
\text { 1.5 Atuação efetiva das lideranças (gestores do parque e demais stakeholders). } \\
\text { 1.6 Presença de uma incubadora de empresas. } \\
\text { 1.7 Qualificação dos empreendedores. } \\
\text { 1.8 Capacidade de atrair e reter talentos. } \\
\text { 1.9 Trabalho em rede estratégico e efetivo. } \\
\text { 1.10 Alinhamento e foco dos stakeholders. } \\
\text { 1.11 Apoio governamental. } \\
\text { 1.12 Equipe de gestão do parque qualificada (com conhecimentos técnicos e de } \\
\text { mercado). }\end{array}$ & $\begin{array}{l}\text { AURP (2013) } \\
\text { Parry (2006) } \\
\text { Phan, Siegel e } \\
\text { Wright (2005) } \\
\text { National } \\
\text { Research } \\
\text { Council (2009) } \\
\text { Saublens et al. } \\
\text { (2007) } \\
\text { Vedovello, } \\
\text { Judice e Maculan } \\
\text { (2006) }\end{array}$ \\
\hline $\begin{array}{l}\text { Processos } \\
\text { internos }\end{array}$ & $\begin{array}{l}\text { 2.1 } \text { Modelo de gestão adequado às características do parque. } \\
\text { 2.2 Assessoria jurídica. } \\
\text { 2.3 Assessoria de mercado. } \\
\text { 2.4 Assessoria tecnológica. } \\
\text { 2.5 Auxílio na captação de recursos públicos e privados, inclusive capital de risco. } \\
\text { 2.6 Acompanhamento do plano de negócios das empresas. } \\
\text { 2.7 Realização de cursos, workshops, eventos e palestras. } \\
\text { 2.8 Prospecção e atração de empresas âncoras. } \\
\text { 2.9 Atração e seleção de empresas com alto potencial inovador. } \\
\text { 2.10 Promoção de redes de parceria e networking (interno e externo). } \\
\text { 2.11 Promoção de comunicação interna e externa. } \\
\text { 2.12 Desenvolver a imagem e a marca do parque, nacional e internacionalmente. }\end{array}$ & $\begin{array}{l}\text { AURP (2013) } \\
\text { Hansson, Husted } \\
\text { e Vertergaard } \\
(2005) \\
\text { Johnson (2008) } \\
\text { Parry (2006) } \\
\text { Saublens et al. } \\
(2007)\end{array}$ \\
\hline $\begin{array}{l}\text { Empresas } \\
\text { residentes }\end{array}$ & $\begin{array}{l}\text { 3.1 Apoio na interação universidade-empresa (projetos de P,D\&I em parceria, captação } \\
\text { de recursos em cooperação, programas de estágio e trainee). } \\
\text { 3.2 Acesso a laboratórios e instalações de pesquisa da universidade. } \\
\text { 3.3 Interação com grupos de pesquisa e pesquisadores (assessorias e consultorias, } \\
\text { transferência de tecnologia, criação de spin-offs). } \\
\text { 3.4 Disponibilidade de serviços de alto valor agregado (assessorias, treinamentos e } \\
\text { capacitações). } \\
\text { 3.5 Reputação do parque. } \\
\text { 3.6 Interação entre as empresas do parque (networking empresarial). } \\
\text { 3.7 Networking com atores estratégicos (grandes empresas, ICTs, parques } \\
\text { internacionais). } \\
\text { 3.8 Acesso a investidores e financiamentos. } \\
\text { 3.9 Infraestrutura física de excelência. } \\
\text { 3.10 Promoção de ações de internacionalização. }\end{array}$ & $\begin{array}{l}\text { AURP (2013) } \\
\text { Hansson, Husted } \\
\text { e Vestergaard } \\
(2005) \\
\text { Johnson (2008) } \\
\text { Parry (2006) } \\
\text { Vedovello, } \\
\text { Judice e Maculan } \\
\text { (2006) }\end{array}$ \\
\hline $\begin{array}{l}\text { Desenvolvimento } \\
\text { científico, } \\
\text { tecnológico e } \\
\text { inovação }\end{array}$ & $\begin{array}{l}\text { 4.1 Apoio na construção de centros tecnológicos de última geração. } \\
\text { 4.2 Modelos para desenvolvimento de spin-offs e startups. } \\
\text { 4.3 Interação com a incubadora de empresas. } \\
\text { 4.4 Convênios e projetos conjuntos com universidades. } \\
\text { 4.5 Estabelecimento de projetos de P,D\&I financiados com recursos públicos ou } \\
\text { privados. } \\
\text { 4.6 Apoio no aporte de recursos para a universidade. } \\
\text { 4.7 Estímulo à produção científica e técnica como critério de desempenho empresarial. } \\
\text { 4.8 Estímulo à geração de propriedade intelectual como critério de desempenho } \\
\text { empresarial. } \\
\text { 4.9 Estímulo à geração de produtos e serviços inovadores de sucesso comercial como } \\
\text { critério de desempenho empresarial. }\end{array}$ & $\begin{array}{l}\text { Bigliardi et al. } \\
(2006) \\
\text { Dabrowska } \\
(2011) \\
\text { Fernandes (2014) } \\
\text { Ferrara, Lamperti } \\
\text { e Mavilia (2016) } \\
\text { Rodeiro-Pazos \& } \\
\text { Calvo-Babio } \\
\text { (2012) } \\
\text { Vedovello, } \\
\text { Judice e Maculan } \\
\text { (2006) }\end{array}$ \\
\hline $\begin{array}{l}\text { Desenvolvimento } \\
\text { socioeconômico } \\
\text { sustentável }\end{array}$ & $\begin{array}{l}\text { 5.1 Atração de empresas inovadoras para a região. } \\
\text { 5.2 Criação e consolidação de empresas de base tecnológica. } \\
\text { 5.3 Fortalecimento e diversificação da economia local por meio da inovação (geração } \\
\text { de renda, empregos e impostos). } \\
\text { 5.4 Atração de investimentos públicos e privados. } \\
\text { 5.5 Inserção/participação da comunidade local em atividades desenvolvidas pelo } \\
\text { parque (workshops, palestras e cursos). }\end{array}$ & $\begin{array}{l}\text { Bigliardi et al. } \\
(2006) \\
\text { Dabrowska } \\
(2011) \\
\text { Ferrara, Lamperti } \\
\text { e Mavilia (2016) } \\
\text { Fernandes (2014) } \\
\text { Rodeiro-Pazos e } \\
\text { Calvo-Babio } \\
\text { (2012) } \\
\text { Vedovello, } \\
\text { Judice e Maculan } \\
\text { (2006) }\end{array}$ \\
\hline
\end{tabular}

Fonte: adaptado de Ribeiro (2017). 
Na segunda fase da pesquisa, o modelo conceitual de referência proposto, estruturado com os cinco construtos e seus indicadores, conforme o Quadro 5, foi então, testado por meio de um survey que alcançou 84 empresas residentes em 15 parques tecnológicos brasileiros. Para tal, elaborou-se um formulário eletrônico no Gmail, que continha três partes integradas: (i) informações gerais da empresa; (ii) grau de importância dos indicadores propostos para cada um dos cinco construtos; e (iii) observações adicionais, caso os respondentes julgassem necessário. A escala de importância utilizada para a classificação dos indicadores continha quatro pontos, com os números: "0" (nada importante); “1" (pouco importante); "2" (importante); e "3" (muito importante). Além disso, foi solicitado que pessoas com conhecimento global da organização e da relação empresa-parque tecnológico respondessem ao questionário de pesquisa.

Para operacionalização dessa segunda etapa, realizou-se novamente uma amostragem por conveniência ou acessibilidade, mas dessa vez de caráter essencialmente virtual. Isso porque foi necessário acessar os sites dos parques tecnológicos, buscando informações sobre as empresas neles instaladas. Nessa busca, a maioria dos empreendimentos mais conhecidos do País foi pesquisada, sendo que dos 24 sites investigados, foi possível coletar dados de contato (site, e-mail e telefone) das empresas residentes em 18 parques. Nos seis restantes não se encontraram as informações necessárias sobre as empresas instaladas ${ }^{5}$.

Em razão de limitações desta pesquisa, seis parques tecnológicos que estão em operação no País e que disponibilizam dados de suas empresas residentes em seus sites não foram acessados ${ }^{6}$. Dessa forma, dos 24 parques tecnológicos que atendiam a duas condições simultaneamente - estar em operação no país e disponibilizar os contatos de suas empresas residentes em seus sites - 18 foram pesquisados, o que corresponde a $75 \%$ do total de parques tecnológicos possíveis, segundo a heurística utilizada.

Vale mencionar que nos 24 parques tecnológicos em questão foram encontradas 586 empresas residentes e graduadas. Nos 18 parques efetivamente pesquisados, foram cadastradas 527 empresas, que foram convidadas a participar da pesquisa por meio do envio de e-mails que descreviam o estudo e solicitavam a participação. Mais informações sobre

\footnotetext{
${ }^{5}$ Esses seis parques foram: TechnoPark Campinas, CIATEC I e CIATEC II (ambos em Campinas/SP), Parque Tecnológico de São Carlos/SP, Sapiens Parque (Florianópolis/SC) e Feevale Techpark/RS.

6 Esses seis parques foram: Parque Tecnológico da Bahia, Parque Tecnológico da Univap/SP, Parque Tecnológico de Santos/SP, Santa Maria Tecnoparque/RS, Parque Tecnológico Ulbratech/RS e Parque Tecnológico de Uberaba/MG.
}

REAd | Porto Alegre - Vol. 24 - No 3 - Setembro / Dezembro 2018 - p. 183-216 
esses parques tecnológicos ${ }^{7}$, total de empresas instaladas em cada um deles e respostas válidas obtidas estão descritas na Tabela 1.

Tabela 1 - Parques tecnológicos participantes e não participantes da pesquisa

\begin{tabular}{|c|c|c|c|}
\hline Parque Tecnológico & $\begin{array}{l}\text { Empresas } \\
\text { contatadas }\end{array}$ & $\begin{array}{c}\text { Respostas } \\
\text { válidas }\end{array}$ & $\begin{array}{c}\text { Taxa de resposta } \\
(\%)\end{array}$ \\
\hline 1. Porto Digital (Recife/PE) ${ }^{1}$ & 223 & 28 & 12,56 \\
\hline 2. BH-TEC (Belo Horizonte/MG) & 17 & 11 & 64,71 \\
\hline 3. Parque Tecnológico de São José dos Campos/SP & 42 & 10 & 23,81 \\
\hline 4. Tecnopuc (Porto Alegre/RS) & 36 & 10 & 27,78 \\
\hline 5. Inovaparq (Joinville/SC) & 9 & 6 & 66,67 \\
\hline 6. Tecnoparq (Viçosa/MG) & 5 & 4 & 80,0 \\
\hline 7. Tecnosinos (São Leopoldo/RS) & 53 & 2 & 3,77 \\
\hline 8. Parque Tecnológico da UFRJ (Rio de Janeiro/RJ) ${ }^{2}$ & 9 & 2 & 22,22 \\
\hline 9. Pólo Bio Rio (Rio de Janeiro/RJ) & 21 & 2 & 9,52 \\
\hline 10. Orion Parque (Lages/SC) & 47 & 2 & 4,26 \\
\hline 11. Parque Tecnológico Itaipu (Foz do Iguaçu/PR) ${ }^{3}$ & 3 & 1 & 33,33 \\
\hline 12. Parque de Software de Curitiba/PR & 11 & 1 & 9,09 \\
\hline 13. Supera Parque (Ribeirão Preto/SP) ${ }^{3}$ & 6 & 1 & 16,67 \\
\hline 14. PCT Guamá $\left(\right.$ Belém/PA) ${ }^{3}$ & 2 & 1 & 50,0 \\
\hline 15. SergipeTec (Aracaju/SE) & 11 & 0 & 0,0 \\
\hline 16. Parque Tecnológico da Paraíba (João Pessoa/PB) & 8 & 0 & 0,0 \\
\hline 17. Parque Tecnológico de Sorocaba/ $\mathrm{SP}^{3}$ & 4 & 0 & 0,0 \\
\hline 18. Parque EcoTec Damha (São Carlos/SP) & 20 & 0 & 0,0 \\
\hline 19. Parque Tecnológico da Bahia (Salvador/BA) ${ }^{4}$ & 3 & 0 & 0,0 \\
\hline 20. Parque Tecnológico da Univap ${ }^{4}$ & 32 & 0 & 0,0 \\
\hline 21. Parque Tecnológico de Santos/SP ${ }^{4}$ & 4 & 0 & 0,0 \\
\hline 22. Santa Maria Tecnoparque (Santa Maria/RS) ${ }^{4}$ & 13 & 0 & 0,0 \\
\hline 23. Parque Tecnológico ULBRATECH Canoas/RS ${ }^{4}$ & 6 & 0 & 0,0 \\
\hline 24. Parque Tecnológico de Uberaba/MG ${ }^{4}$ & 1 & 0 & 0,0 \\
\hline 25. Feevale Techpark (C. Bom/N. Hamburgo/RS) & - & 3 & - \\
\hline Total de empresas & 586 & 84 & 14,33 \\
\hline
\end{tabular}

Fonte: Ribeiro (2017).

Notas: (1) Todas as empresas foram contatadas por telefone, mas algumas não foram encontradas; (2) Foram contatadas (por e-mail) somente pequenas e médias empresas; (3) Número de empresas cadastradas no site do parque à ocasião da pesquisa $\left(2^{\circ}\right.$ semestre/2016); (4) As empresas desses parques não foram convidadas para participar do estudo.

\footnotetext{
${ }^{7}$ Como se pode perceber na Tabela 1, há a identificação de um $25^{\circ}$ parque, o Feevale Techpark. Embora ele não disponibilizasse em seu site informações de suas empresas residentes à ocasião da pesquisa, algumas de suas empresas (incubadas) participaram do estudo, devido ao recebimento de um e-mail de divulgação da pesquisa encaminhado pela Associação Nacional de Entidades Promotoras de Empreendimentos Inovadores (ANPROTEC).
} 
Ao final da coleta de dados, foram obtidos 84 questionários válidos, de um total de 527 empresas contatadas, perfazendo uma taxa de respostas de 14,33\%. Vale observar que nessa amostra estão representadas empresas de 15 parques tecnológicos brasileiros. O número de questionários obtido, apesar de relativamente baixo, é apenas ligeiramente inferior à média constatada em estudos realizados com empresas de parques tecnológicos, que se encontra por volta de 100 casos (VÁSQUEZ-URRIAGO et al., 2014).

Para análise dos dados, foram utilizadas técnicas de estatística descritiva, visando conhecer medidas de centralidade e dispersão dos dados. Posteriormente, os construtos foram avaliados em relação aos critérios de dimensionalidade e confiabilidade, utilizando-se técnicas de análise fatorial exploratória (AFE) e análise de consistência interna, por meio do software SPSS, versão 23. A estrutura fatorial identificada foi purificada, retendo-se itens não ambíguos de maior carga fatorial nas dimensões encontradas, considerando-se também sua consistência interna e a abrangência de representação dos construtos.

\section{RESULTADOS E DISCUSSÕES}

\subsection{ESTUDO MULTI-CASOS}

Para esta análise, apresentam-se inicialmente o contexto e as características dos parques pesquisados e em seguida o conteúdo das categorias temáticas: fatores críticos de sucesso, portfólio de serviços, indicadores de resultados e posicionamento, estratégia e objetivos estratégicos.

O tecnoPARQ (Parque Tecnológico de Viçosa), inaugurado em 2011, foi o primeiro do estado de Minas Gerais a entrar em operação. De uma área total de 214 hectares, 40 são destinados para urbanização e ocupação por empresas de base tecnológica e centros de pesquisa, desenvolvimento e inovação. Como importante âncora possui a Universidade Federal de Viçosa (UFV), referência no ensino e na pesquisa no País, principalmente na área de ciências agrárias. Em 2014, o parque possuía 11 empresas residentes, que faturaram cerca de 5 milhões de reais (tecnoPARQ, 2016).

O BH-TEC (Parque Tecnológico de Belo Horizonte) foi inaugurado em 2012, sendo o segundo do estado de Minas Gerais a entrar em operação. Localizado próximo à Universidade Federal de Minas Gerais (UFMG), possui cerca de $535 \mathrm{mil} \mathrm{m}^{2}$ de área total. Aproximadamente 185 mil $\mathrm{m}^{2}$ são destinados à construção de 12 edifícios, com potencial construtivo estimado em $235.241 \mathrm{~m}^{2}$. O edifício institucional está operando com plena 
ocupação. Em 2014, o parque possuía 16 empresas residentes, que obtiveram um faturamento de 104,1 milhões de reais, pagaram 8 milhões de reais em impostos e empregaram 120 profissionais com nível de pós-graduação (BH-TEC, 2016).

O Sapiens Parque (Parque Tecnológico de Florianópolis) foi inaugurado em 2006, sendo relativamente pioneiro no País. Localizado em Florianópolis, no estado de Santa Catarina, possui uma área total de aproximadamente 430 hectares, com potencial construtivo máximo estimado em 1,3 milhões de $\mathrm{m}^{2}$. Está inserido em um ecossistema inovador, com tradicionais universidades e institutos de pesquisa, a exemplo da Universidade Federal de Santa Catarina (UFSC) e da Fundação Centros de Referência em Tecnologias Inovadoras (Fundação CERTI). Segundo informações obtidas nesta pesquisa, em 2015 o Sapiens possuía 17 empresas residentes, que empregavam 240 funcionários.

\subsubsection{Fatores Críticos de Sucesso}

$\mathrm{Na}$ elaboração das entrevistas semiestruturadas com os gestores dos parques tecnológicos foram considerados os principais fatores de sucesso apontados na literatura: base científica e tecnológica, apoio governamental, mão de obra qualificada, localização, infraestrutura, portfólio de serviços, perfil das empresas residentes e modelos de gestão e governança.

Em contraposição ao elevado número de fatores de sucesso citados pela literatura, os gestores dos parques tecnológicos analisados destacaram simultaneamente apenas dois aspectos como determinantes para o desempenho desses empreendimentos: área física e infraestrutura para o estabelecimento das empresas e fonte de conhecimento próxima (forte base científica, tecnológica, de pesquisa e inovação).

Outros aspectos relevantes mencionados foram: apoio do governo, presença e demanda de empresários, recursos, conexão das empresas com as universidades, cooperação entre as empresas, formação de clusters, equipe de gestão qualificada e com experiência de mercado, serviços de valor agregado para as empresas, cultura empreendedora e gestão descentralizada.

\subsubsection{Portfolio de Serviços}

A variedade de serviços oferecida pelos parques tecnológicos às empresas residentes foi evidenciada em diversas formas de apoio. Entre as que mais se destacaram estão o suporte 
à captação de recursos institucionais ou de investidores, apoio ao desenvolvimento de projetos, promoção de eventos e assessoria jurídica.

Um aspecto do portfólio de serviços foi enfatizado simultaneamente por todos os parques: o networking, ou o trabalho em rede, com universidades, outras empresas e parceiros institucionais. Tal constatação reforça a importância da cooperação institucional entre universidade-empresa-governo para o sucesso desses empreendimentos, consolidando o conceito do modelo da Hélice Tríplice (ETZKOWITZ; LEYDESDORFF, 1999; ETZKOWITZ, 2003).

\subsubsection{Indicadores de Resultados}

Nesta categoria de análise, os gestores destacaram aspectos do desenvolvimento econômico sustentável, por meio da inovação, como principais resultados de um parque tecnológico: produtos e serviços inovadores de sucesso comercial, evolução do faturamento das empresas, fortalecimento da economia local e geração de empregos. Não obstante, outros indicadores de desempenho foram citados, como: registro de patentes, investimentos realizados, internacionalização de empresas, projetos conjuntos entre empresas e outros em parceria com universidades.

Com base na análise das entrevistas e na revisão de literatura, os principais resultados de um parque tecnológico concentram-se em duas principais categorias de desempenho: desenvolvimento científico e tecnológico e desenvolvimento socioeconômico. Na primeira, estão presentes aspectos relacionados às inovações de produtos e serviços e à criação de negócios e empresas de base tecnológica por meio da pesquisa aplicada. $\mathrm{Na}$ segunda, encontram-se os indicadores: geração de empregos, impostos e renda, atrelados ao desenvolvimento e desempenho das empresas do parque.

\subsubsection{Posicionamento, Estratégia e Objetivos Estratégicos}

Importância da incubadora, perfil generalista dos parques, povoamento com empresas da própria região (em geral, micro e pequenas), forte presença do setor de Tecnologia da Informação e Comunicação (TIC) e relevância do estímulo à interação universidade-empresa foram características constatadas nos três parques.

Ainda que os empreendimentos pesquisados encontrem certa dificuldade em estabelecer um perfil mais especializado de áreas de atuação, constatou-se que cada parque 
tecnológico vislumbra definir um posicionamento mais claro no futuro. Assim, o tecnoPARQ deseja especializar-se em toda a extensa cadeia de biotecnologia animal e humana; o $\mathrm{BH}-$ TEC visa concentrar-se nos setores de biotecnologia e tecnologia da informação; e o Sapiens Parque busca destacar-se nos clusters de tecnologia da informação, economia criativa, energia sustentável e ciências da vida, com foco no desenvolvimento de fármacos.

No que se refere às estratégias de desenvolvimento dos parques tecnológicos, que envolvem suas proposições de valor para as empresas residentes, observa-se uma preocupação comum com a promoção da competitividade por meio dos serviços que cada um oferece. Nesse sentido, destacam-se visões como: "Nós focamos muito no amadurecimento desses serviços de valor agregado que a gente presta às empresas" (tecnoPARQ), "A gente tem uma batalha grande nisso daí de criar valor para as empresas" (BH-TEC) e "Nos tornamos mais competitivos oferecendo um serviço melhor" (Sapiens Parque).

De forma mais específica, cada empreendimento estabelece sua própria estratégia de desenvolvimento. No tecnoPARQ, a ênfase é colocada no amadurecimento dos serviços de valor agregado às empresas, até no sentido de superar as dificuldades de sua localização geográfica. Assim, o parque tecnológico busca a competitividade por meio de "uma equipe capacitada e um acompanhamento presente, dando respaldo às empresas e tentando minimizar problemas que possam vir a surgir".

No BH-TEC, busca-se criar a marca de um parque tecnológico que promove o desenvolvimento econômico pautado na inovação e no desenvolvimento de produtos de fronteira. Dessa forma, sua estratégia consiste "na seleção de spin-offs acadêmicas, de empresas de tecnologia relevantes, para o cenário, nem que seja regional, aliado à criação de centros de tecnologia e laboratórios que sejam âncoras para o desenvolvimento de outros empreendimentos".

Já o Sapiens Parque enfatiza o fortalecimento da cooperação universidade-empresa, entendendo que a pesquisa aplicada e a transferência de tecnologias são essenciais para o sucesso do empreendimento. Ressaltando a colaboração entre os atores de inovação (empresas e universidades), "a principal estratégia do parque é a criação de clusters para a geração de produtos, serviços, networking e conexões buscando a competitividade".

Todos os parques tecnológicos destacam a importância do povoamento do espaço físico, com a atração de mais empresas de base tecnológica, empresas âncoras e centros tecnológicos ou de pesquisa. Outra clara dificuldade prende-se à necessidade de expandir e de melhorar a infraestrutura, uma vez que todos os parques pesquisados demandam mais investimentos e maior agilidade nas obras de urbanização e estruturação do espaço físico. 


\subsection{SURVEY COM EMPRESAS RESIDENTES}

A segunda etapa do estudo consistiu na realização de um survey que obteve 84 respostas válidas de gestores e diretores de empresas residentes em 15 parques tecnológicos brasileiros. A seguir apresentam-se os tópicos caracterização da amostra, estatísticas descritivas e dimensionalidade e confiabilidade das medidas.

\subsubsection{Caracterização da Amostra}

A caracterização da amostra da pesquisa foi realizada em relação a setor de atuação das empresas, cargo dos respondentes e porte das empresas residentes (número de funcionários) dessas organizações, conforme apresentado nas Figuras 3, 4 e 5, respectivamente.

Figura 3 - Principais setores de atuação das empresas residentes (\%)

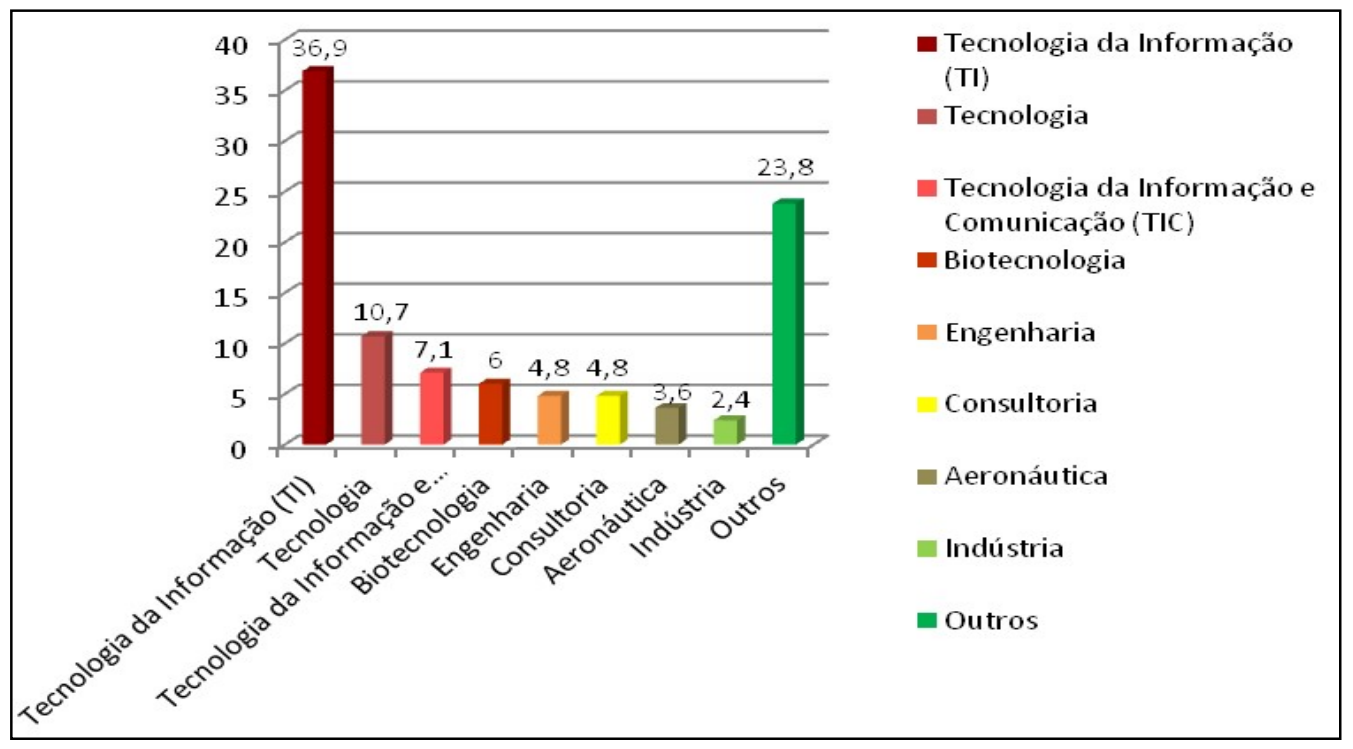

Fonte: Ribeiro (2017).

REAd | Porto Alegre - Vol. 24 - No 3 - Setembro / Dezembro 2018 - p. 183-216 
Figura 4-Cargos dos respondentes (\%)

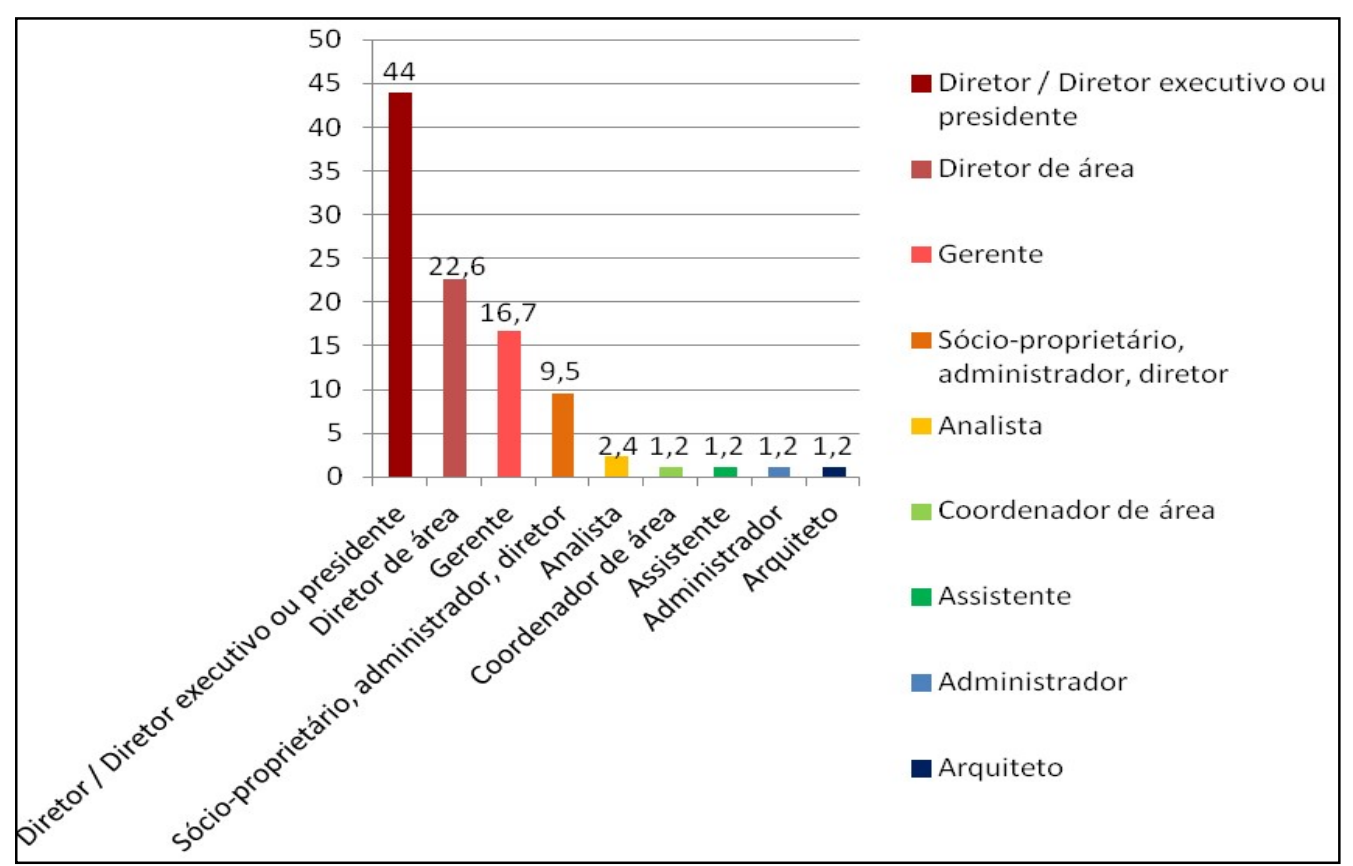

Fonte: Ribeiro (2017).

Figura 5 - Número de funcionários das empresas residentes

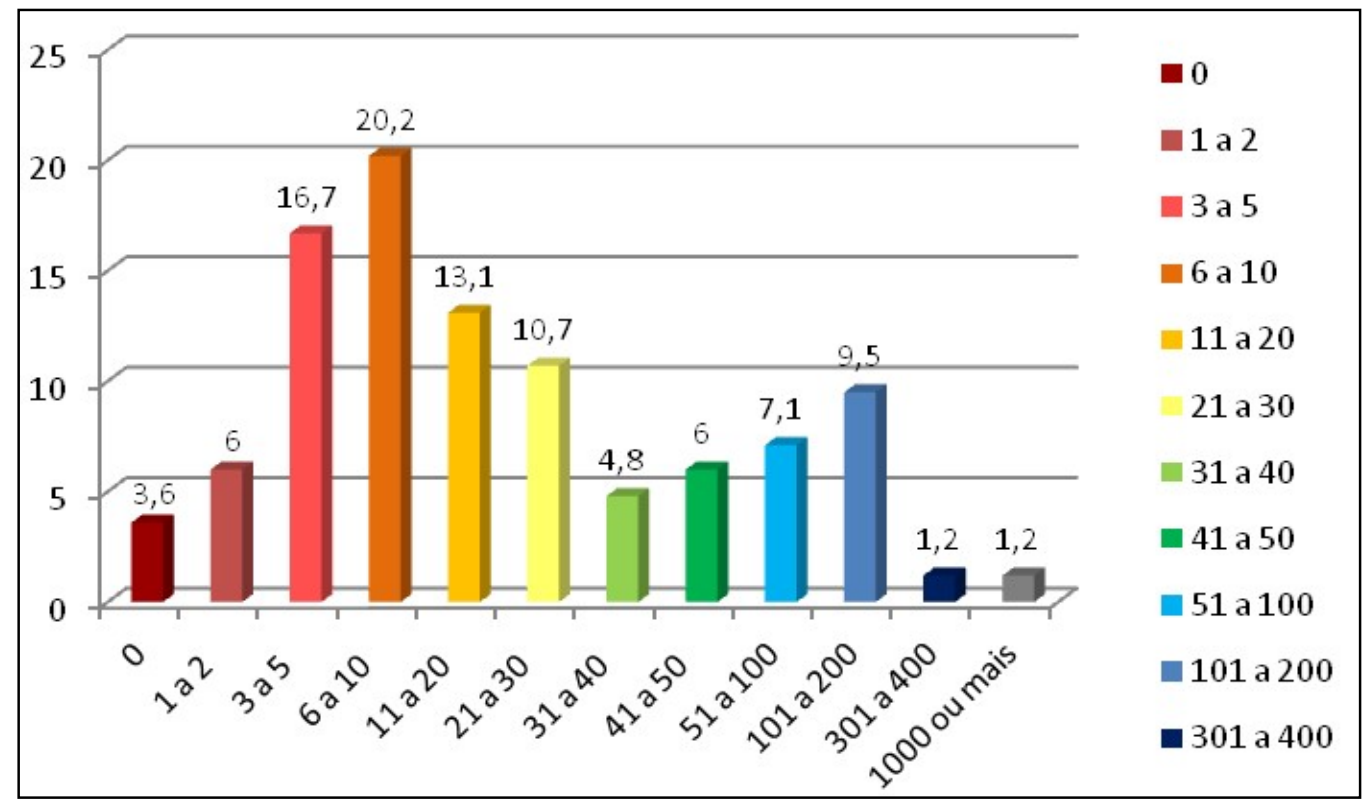

Fonte: Ribeiro (2017). 
Como observado nas Figuras 3, 4 e 5, houve um predomínio de empresas ligadas ao setor de Tecnologia da Informação (37\% da amostra), de respostas provenientes de diretores ou diretores executivos das organizações ( $44 \%$ da amostra) e de empresas na faixa entre 3 e 30 funcionários $(60,7 \%$ da amostra).

\subsubsection{Estatísticas Descritivas}

Ocorreram médias elevadas nos indicadores de todos os cinco construtos do modelo, apresentados no Quadro 5, sendo a média geral igual a 2,3 (em uma escala de 0 a 3), o que indica boa adequação dos indicadores propostos. Os valores do desvio-padrão estiveram entre 0,5 e 0,9, sendo mais altos em indicadores mais controversos, que obtiveram médias menores no questionário.

Para o constructo de aprendizado e crescimento (A\&C), todos os 12 indicadores obtiveram médias superiores a 2,0. Em processos internos (PI), dos 12 indicadores, apenas três apresentaram médias inferiores a 2,0, sendo a média de 1,7 do item 2.6 (Acompanhamento do plano de negócios das empresas) a mais baixa de todos os indicadores do questionário. As 10 variáveis do construto empresas residentes (ER) obtiveram médias elevadas, todas superiores a 2,0. Dos nove indicadores da perspectiva desenvolvimento científico, tecnológico e inovação (DCTI), somente dois obtiveram médias inferiores a 2,0. Por fim, em desenvolvimento socioeconômico sustentável (DSS) houve elevado reconhecimento da importância dos cinco indicadores propostos por parte das empresas instaladas nos parques tecnológicos.

\subsubsection{Dimensionalidade e Confiabilidade das Medidas}

Análises de dimensionalidade e confiabilidade foram realizadas para todos os construtos do modelo. A baixa taxa de respostas da pesquisa, típica de estudos acadêmicos, inviabilizou o atendimento do requisito mínimo de cinco observações por variável (HAIR et al., 2009). Dessa forma, com as 84 respostas válidas obtidas, alcançou-se uma proporção de 1,75 observação por variável, o que representa uma limitação da pesquisa.

A dimensionalidade de uma medida refere-se à homogeneidade de itens, sendo unidimensionais as medidas em que um único fator ou variável latente explica a maior parte da variação associada à inter-relação entre os itens. Problemas de unidimensionalidade 
detectados foram devidamente resolvidos, uma vez que a unidimensionalidade de uma escala ou subescala utilizada para medir um construto é um requisito para sua confiabilidade e validade (NETEMEYER; BEARDEN; SHARMA, 2003).

Conforme sugerem Gerbing e Anderson (1988), empregou-se a análise fatorial exploratória (AFE) para avaliar a unidimensionalidade das escalas de cada construto (conjunto de indicadores correspondentes), verificando-se se o número de fatores retidos na análise fatorial com a extração por componentes principais seria igual a 1 , ao adotar-se o critério de Kaiser (autovalores maiores do que 1), para definir a quantidade de fatores. Consequentemente, foram usadas heurísticas recomendadas por Hair et al. (2009): medida KMO $>0,6$, teste de esfericidade de Bartlett significativo e variância explicada por um fator $\geq 60 \%$.

Inicialmente, realizou-se uma avaliação da unidimensionalidade de cada construto. Embora tenham sido encontrados valores significativos para os testes de Bartlett e KMO > 0,6, apenas a dimensão de desenvolvimento socioeconômico sustentável apresentou unidimensionalidade, sendo que nos demais construtos seria necessário reter de dois a quatro fatores para que a variância explicada ultrapassasse $60 \%$.

Diante dessa constatação, foi necessário verificar a matriz rotacionada por componentes principais (com método de rotação Varimax) de cada um dos quatro construtos e extrair apenas os melhores indicadores (com cargas fatoriais acima de 0,4) que carregavam em uma única dimensão. Foram escolhidas as variáveis que, carregando em apenas uma dimensão, apresentavam os melhores desempenhos relativamente às heurísticas citadas. Houve redução significativa do número de indicadores das escalas, mas garantiu-se a unidimensionalidade dos construtos pelo critério do segundo autovalor menor que 1.

Em todos os construtos, os índices de KMO foram superiores a 0,6 e as variâncias explicadas pelo primeiro fator foram maiores que 45\%. Os resultados das análises de unidimensionalidade considerando-se essa segunda análise encontram-se na Tabela 2.

Comprovada a unidimensionalidade de cada um dos cinco construtos do modelo, prosseguiu-se com a análise de confiabilidade, medida por meio do alfa de Cronbach, cujos valores variam entre 0 e 1 , sendo valores mais elevados indicativos de maior confiabilidade das escalas (HAIR et al., 2009). 
Tabela 2 - Segunda análise de unidimensionalidade usando AFE

\begin{tabular}{|c|c|c|c|c|c|c|c|}
\hline CONSTRUTO & $\begin{array}{c}\mathrm{N}^{\mathbf{0}} \\
\text { INDIC. }\end{array}$ & $\begin{array}{l}\text { VAR. } \\
\text { EXPL. }\end{array}$ & $\begin{array}{c}\text { AUTOVALOR } \\
1^{\circ} \text { FATOR }\end{array}$ & $\begin{array}{c}\text { AUTOVALOR } \\
2^{\circ} \text { FATOR }\end{array}$ & KMO & $\begin{array}{c}\text { SIG. } \\
\text { BARTLETT }\end{array}$ & $\begin{array}{l}\text { INDIC. } \\
\text { RETIDOS }\end{array}$ \\
\hline $\begin{array}{l}\text { Aprendizado } e \\
\text { crescimento }\end{array}$ & 4 & $51,12 \%$ & 2,045 & 0,833 & 0,70 & 0,00 & $\begin{array}{c}1.1,1.6,1.11 \text {, } \\
1.12\end{array}$ \\
\hline $\begin{array}{l}\text { Processos } \\
\text { internos }\end{array}$ & 3 & $62,81 \%$ & 1,884 & 0,651 & 0,65 & 0,00 & $2.5,2.10,2.11$ \\
\hline $\begin{array}{l}\text { Empresas } \\
\text { residentes }\end{array}$ & 4 & $62,45 \%$ & 2,498 & 0,597 & 0,78 & 0,00 & $\begin{array}{c}3.1,3.2,3.3, \\
3.4\end{array}$ \\
\hline $\begin{array}{l}\text { Desenvolvimento } \\
\text { cientifico, } \\
\text { tecnológico } \\
\text { inovação }\end{array}$ & 6 & $58,58 \%$ & 3,515 & 0,803 & 0,81 & 0,00 & $\begin{array}{l}4.1,4.5,4.6, \\
4.7,4.8,4.9\end{array}$ \\
\hline $\begin{array}{l}\text { Desenvolvimento } \\
\text { socioeconomico } \\
\text { sustentável }\end{array}$ & 5 & $47,77 \%$ & 2,389 & 0,956 & 0,70 & 0,00 & $\begin{array}{l}5.1,5.2,5.3, \\
\quad 5.4,5.5\end{array}$ \\
\hline
\end{tabular}

Fonte: Ribeiro (2017).

Os cinco construtos do modelo apresentaram bons índices de confiabilidade ou consistência interna, isto é, acima de 0,6. Vale destacar que os construtos ER e DCTI apresentaram os maiores coeficientes alfa, de 0,80 e 0,86, respectivamente. Os valores da Média de Correlações Inter-itens (MCII) dos construtos estiveram no intervalo de 0,34 a 0,50, podendo ser considerados bons, segundo Robinson, Schaver e Wrigthsman (1991), que defendem uma MCII de pelo menos 0,30. A Tabela 3 resume as análises estatísticas de unidimensionalidade e confiabilidade, com os indicadores que foram retidos, a partir daqueles propostos no Quadro 5, após a análise fatorial exploratória e análise de consistência interna.

Dessa forma, de um conjunto de 48 indicadores propostos para os cinco construtos do modelo de pesquisa, obteve-se, após as devidas análises estatísticas, um modelo mais parcimonioso, com 22 indicadores que refletem os recursos estratégicos mais importantes oferecidos pelos principais atores que compõem o ecossistema do parque tecnológico, de acordo com a visão das empresas residentes nesses empreendimentos, bem como os indicadores de resultados considerados mais adequados para o monitoramento e aperfeiçoamento da gestão de desempenho do parque tecnológico. 
Tabela 3 - Indicadores selecionados do modelo conceitual de referência

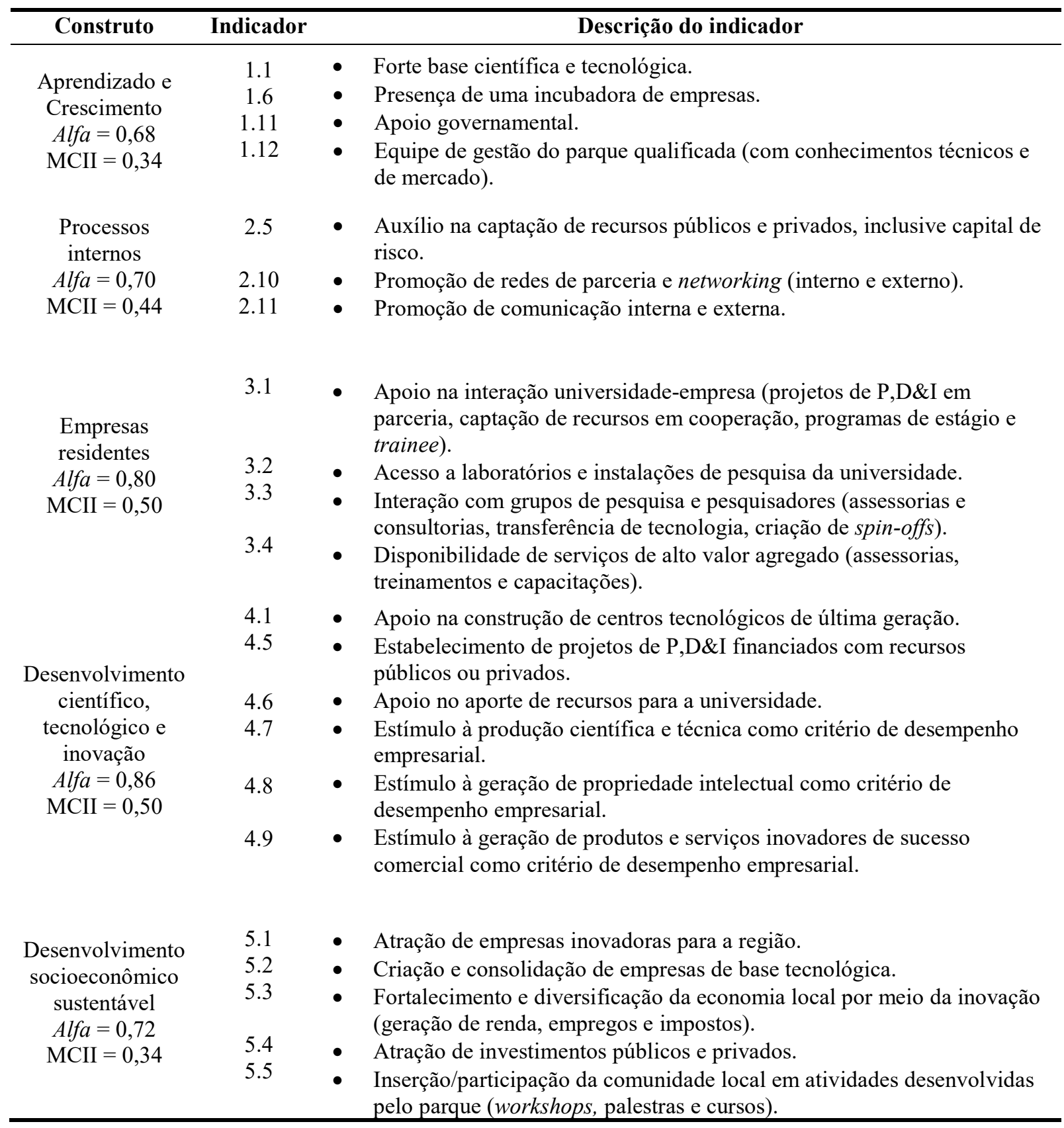

Fonte: adaptado de Ribeiro (2017).

\subsection{ANÁLISE DO MODELO CONCEITUAL DE REFERÊNCIA}

Considerando os resultados alcançados, pode-se afirmar que o modelo de pesquisa proposto apresenta uma abordagem válida, que pode ser utilizada como referência, para o REAd | Porto Alegre - Vol. 24 - No 3 - Setembro / Dezembro 2018 - p. 183-216 
entendimento da governança e gestão de parques tecnológicos. Os indicadores dos construtos aqui apresentados podem ser vistos tanto como fatores críticos de sucesso para justificar a criação quanto para orientar o desenvolvimento de um parque tecnológico. Ainda, podem ser definidos como características, condições ou variáveis que podem ter um impacto significativo na operação do parque tecnológico, sobretudo por buscar o valor percebido pelas empresas residentes. $\mathrm{O}$ estudo desses indicadores está relacionado à identificação das áreas mais críticas de desempenho, à luz do BSC, visando reduzir a complexidade da tomada de decisão e gestão do parque tecnológico.

O construto "aprendizado e crescimento", que se refere aos ativos intangíveis ou à fonte definitiva de criação de valor sustentável, reflete os elementos de capital humano (equipe de gestão), organizacional (incubadoras e universidades) e de ambiente institucional (apoio governamental) indispensáveis à construção e sucesso desses empreendimentos. Esses indicadores podem ser entendidos como pré-requisitos à viabilidade do parque tecnológico, como uma organização intermediária, que auxilia a promoção da inovação, de acordo com a perspectiva da Hélice Tríplice. Esse comportamento também é observado nos demais construtos, em função dos indicadores que reforçam o valor da interação com as universidades e o networking.

O construto "processos internos", que se refere aos poucos, mas principais processos críticos, que fornecem a proposição de valor diferenciada e que mais contribuem para aumentar a produtividade e preservar o funcionamento da organização, mostrou a relevância de três serviços para as empresas residentes em parques tecnológicos: apoio na captação de recursos e financiamentos, promoção de redes de parceria e networking e comunicação/divulgação interna e externa.

O sucesso do construto "empresas residentes" - no caso desta pesquisa, os clientesalvo dos parques tecnológicos - é o principal componente responsável pela melhoria do desempenho científico, tecnológico e de inovação, bem como do desempenho socioeconômico local. Com base nesta pesquisa, pode-se afirmar que as empresas instaladas em parques tecnológicos entendem, como proposta de valor do parque, os benefícios da interação universidade-empresa, o acesso a laboratórios e instalações de pesquisa da universidade, a interação com grupos de pesquisa para transferência de tecnologias e os serviços de alto valor agregado na forma de assessorias, treinamentos e capacitações.

Em relação ao construto "desenvolvimento científico, tecnológico e inovação", são centrais duas percepções, a de que os parques tecnológicos são apoiados pelas universidades e a de que é imprescindível considerar os resultados de desenvolvimento científico e 
tecnológico alcançados ou motivados pela sua criação. Assim, do ponto de vista das empresas residentes, os parques tecnológicos devem apoiar a construção de centros de tecnologia de última geração, o estabelecimento de projetos de P,D\&I financiados com recursos públicos ou privados e a geração de produtos e serviços inovadores de sucesso comercial como critério de desempenho empresarial.

Por fim, em relação ao construto "desenvolvimento socioeconômico sustentável", observou-se que todos os indicadores propostos foram considerados importantes pelas empresas residentes, com menor influência do indicador "participação/inserção da comunidade local em atividades desenvolvidas pelo parque tecnológico". Esse fato demonstra certa dificuldade de as empresas atuarem de forma mais holística, incentivando a criação de políticas que tornem o parque tecnológico um ambiente mais conhecido e acessível à sociedade.

O modelo de referência para a gestão estratégica do desempenho de parques tecnológicos, apresentado na Tabela 3, representa, em essência, um caminho para que os gestores do parque possam estabelecer um sistema estratégico de gestão, capaz de promover alinhamento e foco, considerando a percepção de valor das empresas, os diferentes interesses dos stakeholders e a missão do parque. Esse caminho significa que o parque deve fazer da estratégia um processo contínuo, com a definição de atividades e responsabilidades para todos os envolvidos.

Como modelo de referência para a gestão estratégica do desempenho de parques tecnológicos, sugere-se que os gestores devem adaptá-lo à realidade do empreendimento, definindo métricas para os indicadores que sejam condizentes com a maturidade e a capacidade de recursos do parque, bem como alinhadas ao plano estratégico.

\section{CONSIDERAÇÕES FINAIS}

Parques tecnológicos são empreendimentos que buscam promover o desenvolvimento tecnológico e socioeconômico sustentável, por meio da inovação, coordenando recursos de diversos atores estratégicos envolvidos nessas iniciativas. A integração desses recursos é complexa e o sucesso desses ambientes de inovação, conforme demonstrado nesse estudo, depende de uma série de fatores, tais como presença de forte base científica e tecnológica, cultura empreendedora, recursos públicos e privados, trabalho em rede e desenvolvimento imobiliário e de cadeias produtivas.

Uma questão relevante no contexto desses empreendimentos diz respeito ao 
desenvolvimento de sistemas de planejamento e avaliação de desempenho mais robustos, capazes de serem implantados por gestores e stakeholders, de forma a promover maior integração de recursos e cocriação de valor nesses ambientes, bem como um acompanhamento mais sistemático dessas iniciativas. Em vista dessa necessidade, foi proposto o modelo teórico-conceitual de referência para a gestão estratégica do desempenho de parques tecnológicos baseado na ferramenta gerencial BSC e delimitado pelos fatores de sucesso, portfólio de serviços de valor agregado, indicadores de desempenho e objetivos estratégicos de parques tecnológicos, identificados com base na literatura e no estudo multicasos.

O modelo conceitual de referência proposto para a gestão estratégica do desempenho de parques tecnológicos foi aperfeiçoado com base em análises estatísticas multivariadas, a partir de um survey com 84 empresas residentes em 15 parques tecnológicos brasileiros em operação. Foram alcançados $60 \%$ dos 25 empreendimentos em operação no País que no momento da pesquisa disponibilizavam em seus sites os contatos de suas empresas residentes.

O modelo de referência permitiu evidenciar, de acordo com a visão das empresas instaladas em parques tecnológicos, os principais recursos oferecidos pelo ecossistema de inovação que podem influenciar a cocriação de valor entre os atores envolvidos (stakeholders), bem como as principais formas de medir os resultados dessas iniciativas. Assim, o modelo conceitual auxilia na compreensão de objetivos estratégicos e indicadores de desempenho comuns aos parques tecnológicos, tanto na fase de planejamento quanto na fase de operação, haja vista que permite o estabelecimento de um referencial organizacional do sistema gerencial estratégico de um parque tecnológico.

Dessa forma, o principal resultado prático desse trabalho é o próprio modelo de referência para a gestão estratégica do desempenho de parques tecnológicos, aqui proposto e consolidado empiricamente, uma vez que pode ser utilizado como ferramenta gerencial, que permitirá aos gestores e stakeholders do parque conduzir o planejamento e as ações para o futuro do empreendimento, de uma forma sistêmica e integrada. Esse modelo, estabelecido a partir de indicadores construídos com base no BSC e nos indicadoes de desempenho de parques tecnológicos, devidamente refinados a partir do entendimento de valor das empresas residentes, torna esse trabalho único na literatura, na visão de seus autores. As perspectivas do modelo estão interligadas de forma coerente e representam dimensões de desempenho interno e externo, consideradas estratégicas no contexto dos parques tecnológicos.

Como contribuições teóricas dessa pesquisa, entende-se que o presente trabalho 
representa um avanço no campo de estudos sobre avaliação de desempenho de parques tecnológicos, ao propor, testar e consolidar um modelo de gestão estratégica de desempenho, que não abrange somente indicadores para a avaliação de resultados, mas também os prérequisitos, as ações e os processos de gestão recomendáveis para o sucesso do empreendimento. Dessa forma, pode-se considerar o modelo apresentado nesse trabalho mais amplo (gestão e avaliação), profundo (construção teórica mais consistente) e abrangente (validação empírica robusta, com base na percepção de valor das empresas) que os anteriores propostos na literatura.

Como limitações dessa pesquisa, citam-se o número de questionários obtido e restrições de recursos que impediram a realização de contatos telefônicos com todas as empresas, o que poderia ter aumentado a taxa de respostas. Como sugestão para estudos futuros, percebe-se a oportunidade de desdobrar alguns indicadores de desempenho de forma mais específica, a fim de que sejam objetivamente aplicados, mensurados e trabalhados, com metas e programas de ação, por gestores e stakeholders de parques tecnológicos.

\title{
REFERÊNCIAS
}

\author{
ASSOCIAÇÃO NACIONAL DE ENTIDADES PROMOTORAS DE \\ EMPREENDIMENTOS INOVADORES (ANPROTEC). Disponível em: \\ http://anprotec.org.br/site/sobre/incubadoras-e-parques/. Acesso em: 24 set. 2018.
} ASSOCIATION OF UNIVERSITY RESEARCH PARKS (AURP) \& BATTELLE TECHNOLOGY PARTNERSHIP PRACTICE. Driving regional innovation and growth: the 2012 survey of North American University Research Parks. [S.1.], p. 1-44, 2013. Disponível em: https://aurp.memberclicks.net/.../aurp batelllestudy2012-final.pdf. Acesso em: 10 jan. 2016.

BARDIN, L. Análise de conteúdo. Lisboa: Edições 70, 2000.

BIGLIARDI, B. et al. Assessing science parks' performances: directions from selected Italian case studies. Technovation, v. 26, n. 4, p. 489-505, 2006.

BH-TEC. Disponível em: http://bhtec.org.br/. Acesso em: 08 jan. 2016.

CASTELLS, M.; HALL, P. Technopoles of the world: the making of 21 st century industrial complexes. London: Routledge, 1994.

DABROWSKA, J. Measuring the success of science parks: performance monitoring and evaluation. In: XXVIII IASP WORLD CONFERENCE ON SCIENCE AND 
TECHNOLOGY PARKS. Anais... Copenhagen, 1-23, 2011. Disponível em:

http://repositorio.colciencias.gov.co/handle/11146/265?show=full. Acesso em: 24 set. 2018.

ETZKOWITZ, H. Innovation in innovation: the Triple Helix of university-industrygovernment relations. Social Science Information, v. 42, n. 3, p. 293-337, 2003.

ETZKOWITZ, H.; LEYDESDORFF, L. The future location of research and technology transfer. Journal of Technology Transfer, v. 24, p. 111-123, 1999.

FERNANDES, S. C. R. Avaliação de Parques Tecnológicos: uma proposta de modelo para parques de $3^{\text {a }}$ geração. 2014. 201 f. Dissertação (Mestrado em Administração)-Instituto COPPEAD de Administração, Universidade Federal do Rio de Janeiro, Rio de Janeiro, 2014. FERRARA, M.; LAMPERTI, F.; MAVILIA, R. Looking for best performers: a pilot study towards the evaluation of science parks. Scientometrics, n. 106, p. 717-750, 2016. GERBING, D.W.; ANDERSON, J.C. An updated paradigm for scale development incorporating unidimensionality and its assessment. Journal of Marketing Research, v. 25 (May), p. 186-192, 1988.

HAIR, J. et al. Análise Multivariada de Dados. 6. ed. Porto Alegre: Bookman, 2009. HANSSON, F.; HUSTED, K.; VESTERGAARD, J. Second-generation science parks: from structural holes jockeys to social capital catalysts of the knowledge society. Technovation, v. 25, p. 1039-1049, 2005.

JOHNSON, W. H. Roles, resources and benefits of intermediate organizations supporting triple helix collaborative R\&D: The case of Precarn. Technovation, n. 28, p. 495-505, 2008. KAPLAN, R.; NORTON, D. The Balanced Scorecard: Measures that Drive Performance. Harvard Business Review, v. 70, n. 1 (January-February), p. 71-79, 1992. KAPLAN, R.; NORTON, D. A estratégia em ação: balanced scorecard. 18. ed. Rio de Janeiro: Elsevier, 1997.

KAPLAN, R.; NORTON, D. Mapas estratégicos - Balanced Scorecard: convertendo ativos intangíveis em resultados tangíveis. 9. ed. Rio de Janeiro: Elsevier, 2004.

MCTIC. Estudo de projetos de alta complexidade: indicadores de parques tecnológicos. (versão resumida). Centro de Apoio ao Desenvolvimento Tecnológico. Ministério da Ciência, Tecnologia e Inovação - Brasília: CDT/UnB, 2013.

MCTIC. Propostas de Políticas Públicas para Parques Tecnológicos e Incubadoras de Empresas. (Estudo). Brasília: MCTIC, 2015.

MONCK, C.; PETERS, K. Science parks as an instrument of regional competitiveness: measuring success and impact. In: XXVI IASP WORLD CONFERENCE ON SCIENCE AND TECHNOLOGY PARKS. Anais... Malaga, 1-19, 2009. Disponível em: 
www.sqw.co.uk/files/8113/8712/8061/57.pdf. Acesso em: 21 nov. 2015.

NATIONAL RESEARCH COUNCIL. Understanding Research, Science and Technology

Parks: Global Best Practices: Report of a Symposium. Washington, DC: The National Academies Press, 2009.

NETEMEYER, R. G.; BEARDEN, W. O.; SHARMA, S. Scaling procedures: Issues and Applications. Thousand Oaks: Sage Publications, 2003.

PARRY, M. (Ed.) The planning, development and operation of science parks. 2nd ed. Cambridge: UK Science Park Association, 2006.

PHAN, P. H.; SIEGEL, D. S.; WRIGHT, M. Science parks and incubators: observations, synthesis and future research. Journal of Business Venturing, v. 20, p. 165-182, 2005. RATINHO, T.; HENRIQUES, E. The role of science parks and business incubators in converging countries: evidence from Portugal. Technovation, n. 30, p. 278-290, 2010. RIBEIRO, J. A. Desenvolvimento e validação de um modelo de referência para a gestão estratégica do desempenho de parques tecnológicos. 2017. 160 f. Tese (Doutorado em Administração)-Centro de Pós-Graduação e Pesquisas em Administração, Universidade Federal de Minas Gerais, Belo Horizonte, 2017.

RIBEIRO, J. A. et al. A framework for the strategic management of science \& technology parks. Journal of Technology Management \& Innovation, v. 11, n. 4, p. 80-90, 2016. ROBINSON, J.; SCHAVER, P.; WRIGHTSMAN, L. Criteria for scale selection and evaluation. In: Robinson, J. P.; Schaver, P. R.; Wrightsman, L. S. (Orgs.) Measures of personality and social psychological attitudes. San Diego: Academic Press, 1991, p. 1-15. RODEIRO-PAZOS, D.; CALVO-BABIO, N. El rol de los parques científico-tecnológicos em el empreendimento universitario: propuesta de um catálogo de indicadores de evaluación.

Globalización, Competitividad y Governabilidad, v. 6, n.2, 2012.

SAUBLENS, C. et al. Regional research-intensive clusters and science parks. European Comission, 2007. Disponível em:

https://ec.europa.eu/research/regions/pdf/publications/sc park.pdf. Acesso em: 15 jan. 2016. SAXENIAN, A. Sillicon Valley and Route 128: regional prototypes or historic exceptions? In: Castells, M. (Ed.) High technology, space, and society. Beverly Hills: Sage, 1985. tecnoPARQ (2016). Pesquisa geral no site. Disponível em: http://www.centev.ufv.br/tecnoparq/pt-br/. Acesso em: 07 jan. 2016. VÁSQUEZ-URRIAGO, A. R. et al. The impact of science and technology parks on firms' product innovation: empirical evidence from Spain. Journal of Evolutionary Economics, n. 24, p. 835-873, 2014.

REAd | Porto Alegre - Vol. 24 - No 3 - Setembro / Dezembro 2018 - p. 183-216 
VEDOVELLO, C. A.; JUDICE, V. M. M.; MACULAN, A. D. Revisão crítica às abordagens a parques tecnológicos: alternativas interpretativas às experiências brasileiras recentes.

Revista de Administração e Inovação, v. 3, n. 2, p. 103-118, 2006.

VILÀ, P.; PAGÈS, J. Science and technology parks. Creating new environments favorable to innovation. Paradigmes, n. 0, p. 141-149, 2008.

\section{APÊNDICE}

\section{Roteiro de entrevista do estudo multicasos}

1. Quais são os principais stakeholders considerados na gestão do parque? O modelo Hélice Tríplice (governo, academia e empresas) é uma boa referência de análise ou poderiam ser incluídos outros grupos de interesse?

2. Qual é a contribuição de cada stakeholder e quais são os resultados que cada um deles espera obter?

3. Em que fase do ciclo de vida você considera que este parque está? Inicial, de crescimento ou maduro?

4. Como este parque pode ser caracterizado em relação aos seguintes eixos:

1. Urbano / Não-urbano

2. Ênfase na pesquisa / no mercado

3. Empresas-alvo: nascentes (EBTs) ou maduras

4. Parque especialista ou generalista

5. Mercados-alvo locais/regionais ou internacionais

6. Trabalho em rede ocasional ou estratégico

7. Modelo de gestão do setor público ou do setor privado

5. No seu entendimento, quais são os fatores críticos para um parque tecnológico de sucesso? Este parque possui todos eles?

6. Na sua visão, quais são os resultados esperados de um parque tecnológico? Quais destes são gerados pelo parque?

7. A equipe de gestão do parque utiliza alguma ferramenta ou metodologia para a gestão estratégica do empreendimento? (Análise SWOT, fatores críticos de sucesso, planejamento estratégico, comparação com outros parques em situação semelhante, benchmarking, Balanced Scorecard)

8. Qual é a estratégia do parque para buscar a competividade e ser bem-sucedido? (Temas chave que compõem a estratégia da organização; Proposição de valor da organização) 
9. Quais são os objetivos estratégicos do parque para os próximos anos? Como eles se relacionam?

10. Existem medidas (indicadores), metas e iniciativas traçadas para o alcance destes objetivos? Com que frequência tais parâmetros são avaliados formalmente?

11. São desenvolvidas iniciativas (ou programas estratégicos) para monitorar e influenciar os atuais indicadores?

12. Quais são as principais dimensões e indicadores utilizados para se monitorar o desempenho do parque? (Por exemplo, financeira, mercadológica, tecnológica, serviços de apoio/processos internos, bases de crescimento).

13. Quais são os principais segmentos de clientes que as empresas do parque almejam alcançar? São clientes regionais, nacionais ou internacionais?

14. E quais são os principais concorrentes das empresas do parque? São concorrentes regionais, nacionais ou internacionais?

15. Existe uma clara estratégia de posicionamento para o parque e suas empresas? (produtos e serviços de maior valor agregado, produtos competitivos e de qualidade, reconhecimento de marcas e produtos do parque, produtos e serviços inovadores, acelerar o crescimento da agroindústria ou do produto industrial, entre outros).

16. Quais seriam os principais processos internos da cadeia de valor do parque (gestão operacional, gestão de clientes, inovação e regulatório e social) nos quais a equipe de gestão trabalha? Eles são suficientes ou seria necessário desenvolver outros serviços de apoio para aumentar a competitividade do parque? Quais são os temas estratégicos da perspectiva interna?

17. Quais são, na sua visão, os principais aspectos de infraestrutura, capacitação e competências em que o parque precisa crescer? 